\title{
INFLUENCING GEOMETRICAL PARAMETERS OF TOOLS IN FRICTION STIRRING TECHNOLOGY: A SHORT REVIEW
}

\author{
SANJAY Sharma ${ }^{1 *}$, AMIT Handa ${ }^{2}$, SAHIB Sartaj Singh ${ }^{3}$ \\ ${ }^{I}$ School of Engineering, BFIT, Dehradun, India, e - mail: mesunjay@gmail.com \\ ${ }^{2}$ Department of Mechanical Engineering, I.K. Gujral Punjab Technical University, Kapurthala, India. \\ ${ }^{3}$ Department of Mechanical Engineering, Punjab University, Patiala.
}

\begin{abstract}
Friction stirring based "Green" processes are ruled by geometrical and process aspects of the tools used for generating desired properties in the processed materials. Considering only geometrical aspects, the developments in tool geometry, its modifications with the time, profiles and their corresponding impacts on the property generation are addressed in the present work. It is a censorious and judicious review which consolidates the relevant information apropos of all geometrical aspects of tools and their roles in property generation.
\end{abstract}

KEYWORDS: Friction Stir Welding (FSW), Friction stir processing (FSP), Friction Stirring (FS)

\section{Introduction}

Friction stir processing (FSP) is a modified version of Friction Stir Welding process (FSW)and it is well recognized as a "Green" process for significant grain refining [1] - [6], super plasticity improvements [7] - [9] and composite fabrication [6], [10] - [15]. The basic difference between other conventional welding and processing techniques is that heat is not added to the system but generated within the system due to friction in between the rubbing action of tool-material interface surfaces. The heat developed is sufficient to plasticize material under the tool shoulder and results in a subsequent dynamic recrystallization.

As the heat generation in FSW/FSP, depends largely on the tool geometry and its processing parameters which makes it a basic and most important element of the process. The tool of FSW/FSP comprises a shank with a shoulder of bigger diameter and attached with a protruded pin of smaller diameter, at the bottom of the shoulder. The pin length is always kept less than the plate thickness of the material under process. The geometrical aspects and process parameters are leading factors of the friction stirring process corresponding to the tool and it's working. Both the aspects have their own impact on a generation of different properties in resulting material and contribute to the success and quality of the process at large.

Both the aspects, along with their impacts are substantially addressed and analyzed by different researchers. In case of geometrical parameters, scholars have focused on impact of tool design and its geometry, such as influence of tool pin design and its geometry, impact of shoulder profile and geometry and effectiveness of tilt angle values of the tool [16] - [20]. Also, process parameters are studied for enhancement of different mechanical properties, such as improvement of microstructure, grain refinement and homogeneous distribution of alloying elements throughout the specimen [1] - [3], [21] - [23].

Although available reviews in past are successfully focused efforts in the direction of understanding the influence of geometrical aspects of tools on to the processed materials [24] $-[27]$ and different patents filed for the developments in tools, still a consolidation of relevant 
information is required along with addition of recent studies and latest developments. This paper judiciously and critically reviews the contributions of different recent studies dedicated on several geometrical aspects of FSW/P tools, such as pin profile, shoulder diameter, axial load applied and tilt angle values, along with the previous literature. Other relevant topics such as tool materials used, along with their selection criterion, tool wear and tool failure caused due to geometrical aspects, are added to provide an enhanced perceptive of different specifics related to the quality of the processed material.

\section{Friction Stir Processing Technique}

Friction stir processing is an advancement of FSW, which is a joining technique developed by The Welding Institute (TWI) of Cambridge, England, in 1991, patented as 9125978.8[p]. In FSP, a cylindrical tool with shoulder and a protruded profiled pin, as shown in figure 1, is rotated and gradually inserted into the material, as similar to FSW. Initially, the pin is rubbed against the material and plasticize the same due to frictional heat, which allows further stem of the pin to be plunged till the tool shoulder starts rubbing the material under processing. The abrasion of the shoulder of larger diameter provides more friction and corresponding larger heat, which is sufficient to plasticize the material beneath the tool shoulder [28]. The plasticized material revolves with the tool pin in the direction tool rotation and then the tool is than transverse in the direction of processing to improve the properties.

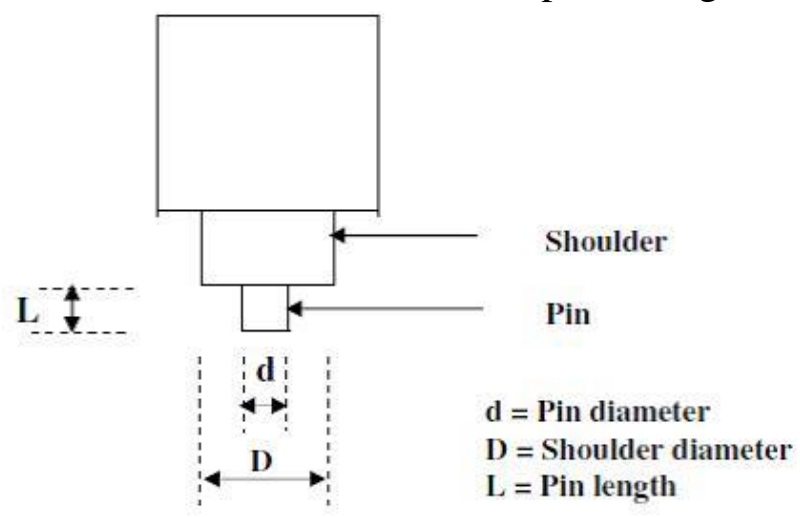

Fig. 1 (FSW/P Tool)

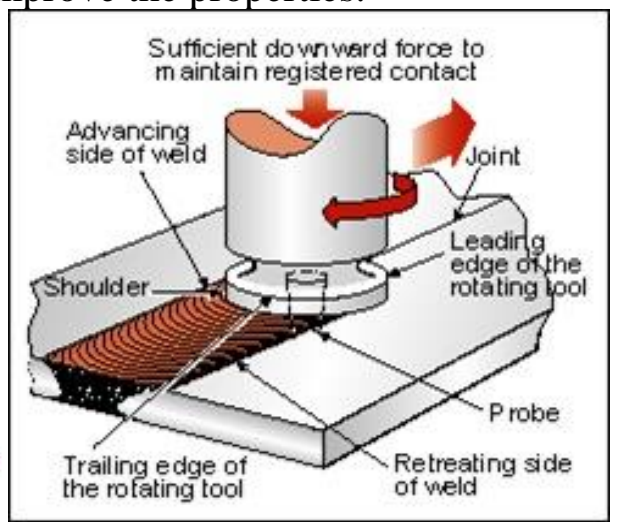

Fig. 2 (Schematic diagram of FS process)

This develops two sides about the rotation axis as an advance side and retreating side and the plasticized material is moved by the pin rotation from advance side to the retreating side of the tool pin. The deposition of material is in continuous layers on one over the other, in a forged manner. This forging action is caused by the following plasticized material, which is forcefully driven by the tool shoulder and pin rotation and deposited on to the retreating side. This fills all the voids and cracks in the material structure under process. In case of FSW, the joint produced by this continuous addition of plasticized material is said to be "solid state joint"[2].

The inherent advantages of the process of Friction stirring, such as improvement in the microstructure of the material especially grain refinement and homogeneous particulate distribution, this phenomenon has been extended to the processing of commercially available metals, alloys, and composites and termed as Friction stir processing (FSP). Friction stir processing has now established itself as most energy efficient process adopted for improving various properties of metals, alloys, and composites.

Other added advantages of FSP includes enhancement of properties such as, ductility/elongation, fatigue, corrosion properties and hardness [2], [29], which is attained 
through dynamic recrystallization, grain refinement, densification and homogenous distribution of alloying elements.

As in case of FSP, both the tool and the material under process, are subjected to a considerable amount of frictional heat, which is of the order of 70 to $80 \%$ of its melting temperature [30], [31]. This elevated temperature causes dynamic recrystallization of the material under process.

Friction in between the tool and the work material is the main cause of heat generation and depends on tool geometry and processing aspects. This paper focuses on geometrical aspects of the tool responsible for heat generation and resultant properties in the processed material. Tool geometry, being an important factor, plays a fundamental role in property generation and property enhancement due to microstructural modification in the resulting material. At fixed process aspects such as plunge depth, spindle speed, and transverse feed rate, the heat generation in the process depends on:

- Area and surface condition of surfaces in contact of Tool and Workpiece

- Material Flow beneath Tool shoulder

- Axial Pressure exerted on to the Workpiece [32].

As stated, in FSW/FSP, mutual rubbing of the tool pin base and material generates the heat which plasticizes the material and helps the plunging of tool pin inside the under process material. The deformation of the material also contributes in addition to heat and corresponds to dynamic recrystallization of the material under processing[33]. The resulted grain structure after the dynamic recrystallization is considerably fine [34], and corresponds to an enhancement of properties of the material and homogeneous distribution of particulate if intended.

\section{Different Tools Materials used for Friction Stir Welding and Processing}

As in case of Friction stirring processes, to plasticize the material under processing, tools are either inserted into a tight gap in between the two materials to be joined (FSW) or directly plunged inside the material for property enhancement (FSP). Therefore, the tools of friction stirring processes are subjected to harsh process conditions such as initial plunging force, large amounts of heat and opposing forces during transverse. This makes the selection of an adequate tool material, a critical factor, which is to be carefully chosen to make the processing successful.

Due to the harsh working conditions the FSW/FSP tools usually degraded and worn out quickly, which makes tool degradation an influencing factor in the process. Degradation of tool defies tool durability and improved related costs, which correspondingly affects the quality and economy of the processed materials [35] Therefore, consideration and prior estimation of the extent of tool degradation in any performance of friction stirring is an inevitable factor, as stated in patented as 9125978.8[p]. Different tool materials are studied by Ramachandran et al. [36], during FSW of high melting temperature materials, and they observed a severe degradation of tools during the process because of harsh working conditions. Sometimes processing parameters and tool material both impact on property generation, as reported by Pilchaket et al. [37], while FSW of Ti-6Al-4V alloy. They reported generation of different microstructures in stir zone as an impact of processing parameters and tool material.

Though being acquainted with many merits still the application of Friction Stirring process is very restricted due to specifically inflexible demands of appropriate tool material. Some 
most desired properties of the tool material, such as higher compressive yield strength at elevated temperatures, dimensional stability and creep resistance [2]. In addition to above, high thermal fatigue strength is required, as FSW/FSP tool is subjected to heating and cooling cycles repeatedly and lower values of coefficient of thermal expansion are a prerequisite in the reduction of thermal stresses in between pin and shoulder material. The use of a thermal barrier coating in case of polycrystalline cubic boron nitride (PCBN) tools and shanks of tungsten carbide tools are preferred to bar the heat conduction. Also, as per FSW technical handbook of Welding Automation (SE-695 81LAXA), wear resistance of tool material is also a critical criterion so as to ensure that no traces of tool material should be left in the processing zone.

Various tool materials are used for FSW/FSP processes, ranging from steels to ceramics.

\subsection{Tool Steel}

Being most common tool material, Tool steel is widely used for welding and processing of aluminium and its alloys, copper and its alloys and magnesium and its alloys. It is capable of welding and processing up to $50 \mathrm{~mm}$ thickness in case of above-mentioned materials and alloys [31]. AISI H13 grade steel is most commonly used tool material, among all other grades. It is air hardened chromium-molybdenum steel has an ability to maintain its strength at elevated temperatures [23], [38]. Tool steels are easily available in various grades glued with inherent properties of adequate machinability and thermal fatigue resistance. Also, steels are damage and abrasion resistant while processing or welding low melting temperature metals and alloys, along with its capability of welding and processing both similar and dissimilar metal alloys.

\subsection{Polycrystalline cubic boron nitride (PCBN)}

Polycrystalline cubic boron nitride was initially developed for machining of hard metals and alloys such as different grades of steels cast iron and super alloys [29], [39]. Due to their special qualities of high mechanical and thermal performance at elevated temperatures, PCBN is a well-accepted material for making FSW/FSP tools. PCBN is acknowledged as the second hardest material and it is harder than the oxides, nitrides, and carbides of ceramics. It is developed by sintering $1-10 \mu \mathrm{m}$ size of CBN particles with a variety mix of ceramic and metal phases, by applying high temperatures and pressures to obtain a solid PCBN mass [4]. Due to the incurred cost in its manufacturing, limitation of sizing, low fracture toughness and extremely poor machinability, its use is constrained. Still it is preferred for abrasive harder work of hardness more than 45 HRC. Sometimes, tool wear leaves traces of tool material in the processed region due to its poor wear resistance. PCBN has the inherent property of good wear resistance and its ability of high thermal stability and sustainability at elevated temperatures makes it a suitable tool material for friction stirring technology. It is most commonly used for FSW/P of steels and Ti alloys. Although it was originally developed for machining tool steels of different grades, but being glued with a property of lower coefficient of friction, it yields smoother welded portions [27] and avoids development of hot spots on tools, due to its high thermal conductivity.

\subsection{Nickel and cobalt-based superalloys:}

Most desired properties of high strength and ductility make this material eligible for an FSW/FSP tool material. Initially, it was developed for making aircraft engine components, but properties like good creep and corrosion resistance make it more applicable for the longer duration of working and now it is well recognized as FSW/P tool material. The abovementioned properties make Nickel cobalt superalloys, a difficult material to machine and 
shape, especially in case of complex design requirements such as flutes and flats on tool pin, in case of FSW/P tools. This affects the economy of the tooling and correspondingly restricts its application as a common tool material.

\subsection{Tungsten based tool materials/ Refractory metals}

The materials such as tungsten, molybdenum, niobium, and tantalum, being produced from single phase materials, have remarkable high-temperature strengths and maintain their properties up to 1000 to $1500{ }^{\circ} \mathrm{C}$. But they are hard for processing due to poor machinability; therefore, sintering technology is preferred as a base method for development of tools.

Siddiquee et al. [40] conducted a tool degradation study on tungsten carbide (WC) for FSW of thick plates of AISI304 stainless steel. They reported plastic deformation and wearing as two aspects for degradation of the tools, which is caused due to different higher affecting loads. Also, Thompson et al. [41] examined three different tungsten based tool materials such as rhenium, hafnium and lanthanum oxide in different changing proportions, alloyed in high strength steel for making the tools for an FSW process. An increase in tool life has been observed by addition of different alloying materials, such as $10 \%$ in case of hafnium and $20 \%$ in case of rhenium in the base metal as compared to $\mathrm{W}-1 \% \mathrm{La}_{2} \mathrm{O}_{3}$ and $\mathrm{W}-25 \% \mathrm{Re}$ materials.

\subsection{Ceramic particle reinforced}

Ceramics also can be used as FSW/FSP tool material due to its high heat resistant sustainability. Though it is brittle enough and generally fractures in initial stages of plunging, but still preferred because of its remarkable hardness and heat resistance property, as compared to carbides. Ceramics are broadly categorized into two segments as alumina-based ceramics, used for ferrous and nonferrous materials and silicon nitride based ceramics, used for processing superalloys.

\section{Selection of Tool material}

Mostly tools get damaged during initial plunge stage being subjected to high impact loads, due to poor fracture toughness. This results in inadequate material stirring and corresponding non-uniform grain refinement of metal stir zone, which is a violation of the inherent and prime benefit of the FSW/P process itself. Therefore, it is desired that the selected tool material must sustain the various forces generated during the initial plunging state of the tool and during the transverse of the tool along the weld/processing direction [42]. This makes good fracture toughness is a mandatory quality in the tool material along with some inherently required properties for any of the tool material as its cost-effectiveness and good machinability, which makes it economical for general acceptance.

In addition to above, selection of the adequate tool material depends on the properties of the material to be processed and processing parameters used. Although different researchers have used different tool materials for different materials, ranging from tool steels to carbides and PCBN, still most common material for tools is tool steel which can be preferred for a maximum of the common materials under processing.

Also, plastic deformation of tool material causes bulging at the tool shoulder, which corresponding increases tool pin taper angle and affects the properties of the processed material [40]. Tool wear, in case of an FSW/ FSP tool, was generally observed at the base of the pin, i.e. on the bottom face of the pin, which is caused due to diffusion and attrition tool wear mechanisms on tool shoulder and pin surface. 
These facts establish tool selection as a key feature for a quality generation in case of Friction stirring technology. The selection of tool material depends on the quality of the material which is to be processed or welded. A proper tool material can contribute in avoiding interaction gap between two consecutive cycles, along with eliminating the defects of wormholes, pinholes and tunnel defect at the advancing side, besides its sustainability in harsh working conditions. It becomes more vital in case of high melting temperature metals and alloys such as steels, titanium and reinforced composites [36].

W. Gan et al. [43] stated that any systematically focused research on tool material selection methodology has not been made and further scope of research is available in this area. Rai et al. [27] affirmed that quality and microstructural properties of the weld are highly influenced by the tool material used. They documented some desired properties which can be considered while in selecting an adequate tool material for any FSW/FSP process. They stated that, the strength of the work material determines the stresses induced on to the tool and corresponding amount of heat generation in the process. Therefore hardness, ductility, and reactivity of the work govern the selection parameters for an adequate tool material, in company with properties like temperature sustainability, thermal conductivity, and coefficient of thermal expansion, which are needed for a successful friction stirring process.

\section{Different parameters associated with FSW/P}

The process of FSW/ FSP is governed by two different set of variables i.e. geometrical parameters of the tool such as shoulder diameter and shape, pin size and shape and process parameters, such as rotational speeds, transition speeds of the tool, axial load on tool and tilt angle of a pin, while processing. Wearing and failure of FSW/FSP tool have their own impacts on the process and corresponding results. Present work is focused on geometrical parameters of the tools and their impact on processed materials.

\subsection{Geometrical parameters of the tool}

The geometrical parameters of tools are principally accountable for adequate heat generation needed to plastically melt the material and transferring this plasticized material from advancing side to retreating side [44]. In Friction stirring processes, geometrical and design features of the tool are considered as a crucial and pivotal factor for generating a quality in the weld or in the processed material surface. Also, they significantly contribute in the effective and efficient utilization of the friction stirring process for a wide variety of metals, alloys, and composites of various thicknesses [45]. This motivated many researchers to study and scrutinize the effects of the prominent geometrical features of the tool along with their influences on the processed material. The open literature available offers several examples of different studies on the effect of the pin geometry [16] - [20], [24], [30], [46] - [49], and established it as a key factor in obtaining the desired results. Recently this statement has been well supported by finite element analysis (FEA) [46], [48], [50], where the analysis of the tool and process proves the considerable impact of tool geometry on desired qualities of the work material. Rai et al. [27] detailed various aspects of friction stirring tools and elaborated tool degradation mechanisms along with tool economy. A feasibility study conducted by the authors by FSW of high melting temperature materials concluded that degradation of the tool also depends on adequate tool geometrical parameters and selection of tool material for a process. Also, Elangovan et al. [51], [52] reported that mechanical properties of Aluminium joints were considerably affected by the geometrical profile of the tool, in their experimentation. H.K Mohanty et al. [53], experimented with three different tool geometries and concluded that geometrical parameters of the tool have a considerable impact on grain refinement and a corresponding improvement in microhardness and strength of the weld. 
Different parameters related to geometrical aspects are Tool shape, shoulder diameter, shoulder surface, pin geometry and tilt angle. The tilt angle is aspect related to process parameter still it is taken into consideration is providing an angle to the tool pin and governs the material flow in the stir zone.

\subsection{Tool Shape}

Friction stirring tools can be classified as fixed, adjustable and self-reacting, on the basis of shape. In the fixed type of tool shape, the tool is a single piece of metal machined to generate both, tool shoulder and pin (Figure 1). This tool is the most commonly used and capable for both the processes welding and processing, up to thickness as per the length of the pin. The pin length is always kept less than the plate thickness, so as to avoid any penetration of the tool through the material. In case of tool degradation or pin wear, the complete tool has to be replaced. Skinner M. et al. [54], devised a concept of Self Reacting type of FSW tool, which is an adjustable type of tool, constitutes with two shoulders that are arranged at top and bottom of the workpiece, which is to be welded. These independently actuated parts are to follow a specified profile and supply a balanced load to the opposite surfaces during the process. This type of tool is only meant for welding purposes so far. The authors presented their design (Figure 3) and experimentally shown the successful welding of aluminium plates of thickness $8 \mathrm{~mm}$ to $25.4 \mathrm{~mm}$. Also, welding of dissimilar and tapered pieces was found achievable.

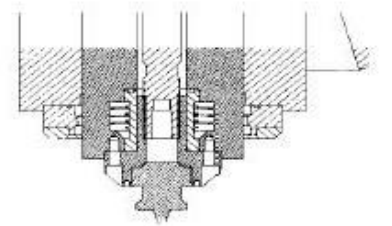

(a)

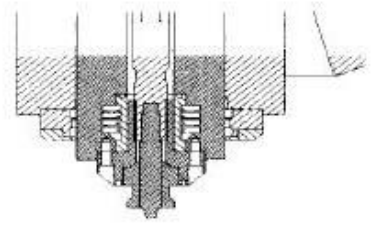

(b)

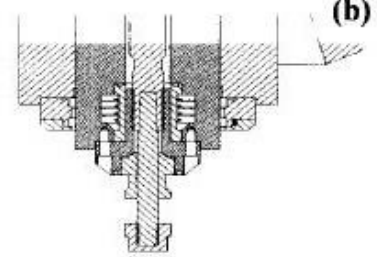

(c)

Fig. 3 Adjustable Type Of Tool Design [512]

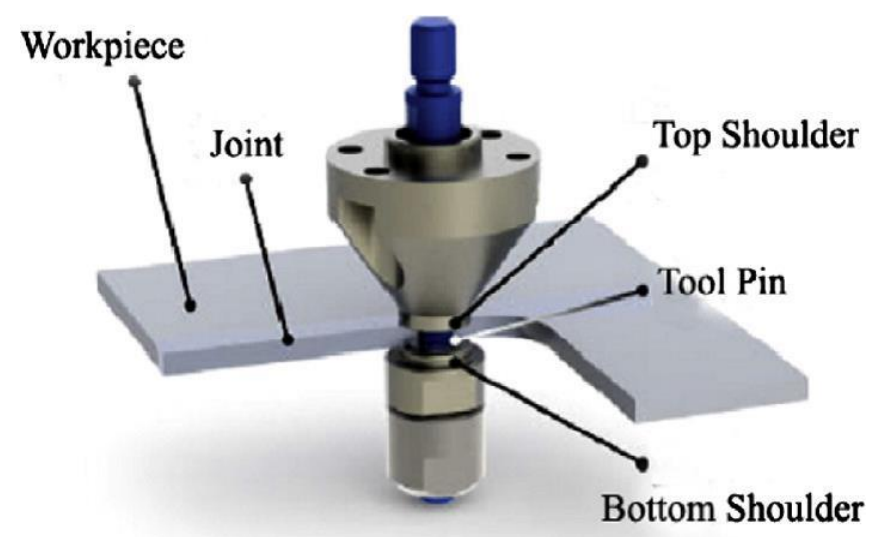

Fig. 4 Dual Side Gripping Tool [53] 
The third type of tool is bobbin tool, which uses both the sides for generating heat through rubbing for welding. It consists of two rotating shoulders, which are connected by a pin, same as earlier, in case of Self Reacting type of FSW tool. The top shoulder acts on the upper surface of the workpiece and the bottom shoulder grips the bottom plate surface [55]. Due to dual side gripping of the workpiece, the load is confined within the tool itself (Figure 4).

W.Y. Li et al. [55] reported generation of equiaxed grains in TMAZ, by the use of this tool, instead of twisted elongated grains as in case of conventional tools. Also, coarse grains are found present in upper and lower of SZ. In bobbin type tool (Figure 4), shoulders can be detached to accommodate different thicknesses of the joint. Being having separable parts, different materials can be chosen for different parts, as per the requirement of the process and piecewise replacement can be done in case of wear or damage. There is no requirement of any backing plate, as in case of conventional tools. However, it is limited to work perpendicularly on to the workpiece surface, as compared to fixed conventional and adjustable tools, as they can be operated either side tilted i.e. longitudinally and laterally.

Threadgill et al. [56] reported obtaining a rectangular cross-section of the processed zone with bobbin tool, as compared to a triangular zone as in case of conventional FSW/FSP tool designs. Also, use of bobbin tool, nullifies the axial load considerably, which is advantageous in context with the design of mechanism and costing of the tooling, along with improved efficiency and application in industry.

In case of FSP, especially when the homogeneous distribution of reinforcement of particulates is required, Y. Huang et al. [57], suggested a hollow Direct Friction Stir Processing (DFSP) tool, without any pin and consisting of a concave shoulder (Figure 5). Conventionally reinforcement particulates were placed either in a pre-generated groove or pre-drilled holes and later on, a pinned tool disperses them during the processing. But authors suggested direct friction stir processing tool, through which reinforcement particles are supplied to the processing zone through a pre-generated hole in the tool itself and get dispersed.

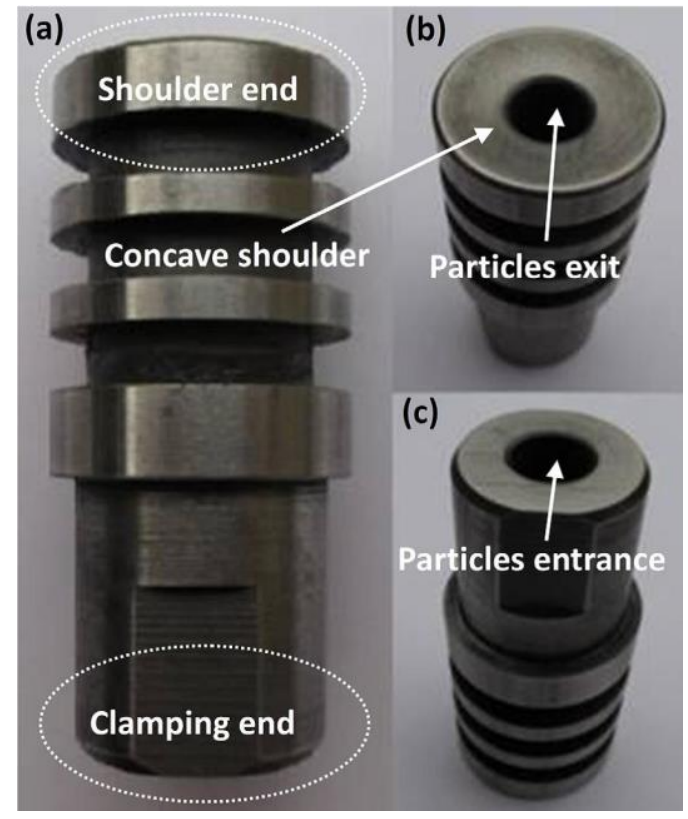

Fig. 5 Direct Stir Processing Tool a) Front view b) Shoulder side View c) Clamping side View, from [57] 
The main advantage of this type of tool is, rather being driven along with the stirring tool for dispersion; reinforcement particles are confined in the space between the concave shoulder and workpiece and dispersed uniformly in the stir zone.

\subsection{Shoulder Diameter}

In any Friction Stirring process, both parts of the tool, i.e. tool shoulder and tool pin, are considered as influencing factors for heat generation, deciding dimensions of the processing zone and material flow in stirring zone. The tool with a larger shoulder area generates more friction and corresponding high heat, hence allows more plastic deformation and material flow behavior is largely governed by pin shape and profile and shape of pin profile [44].

Different scholars have studied the impact of shoulder diameter on different mechanical properties resulted due to modification of microstructure of the metal, after processing. Prominently, Scialpi et al. [17] studied the effect of different shoulder geometries and reported that while joining thin sheets, tool shoulder with a combination of fillet and cavity, resulted in sound and defect free joints. Many researchers have analyzed the merits and demerits of various designs of shoulder profiles. Galvao et al. [58] focused their study on scroll shoulder concept and reported that scrolled shoulder design contributes inadequate heat generation in the stir zone and simultaneously apply confining pressure to the plasticized material for sufficient mixing. Also, R. J. Heideman, stated in their patent application no. PCT/US99/10672, that the tool shoulder is responsible for material consolidation and confines displacement of the material within the processing area. It also helps in rendering smoothness of the generated surface, which contributes to aesthetics of the weld or surface. Frigaad et al. [59] calculated the average heat input per unit area and time for an age hardenable aluminium alloy from the equation (Equation 1), which can be referred to exhibit the impact of tool shoulder profile and amount of heat generation.

$$
\mathrm{H}=4 / 3 \pi 2 \mu \mathrm{P} \omega \mathrm{R}^{3}
$$

Where $\mathrm{H}$ is the amount of heat generated, $\mu$ is the effective friction coefficient in between the tool and workpiece surface in contact, P is the axial load applied (in M Pa), $\omega$ is the rotational speed (rev./min) and $\mathrm{R}$ is the shoulder radius $(\mathrm{mm})$.

From equation 1, It is clear that the heat generation depends on the value of the radius of the shoulder and effective coefficient of friction acting in between workpiece surface and the tool.

Furthermore, the FSW/FSP surfaces processes traces of circular arcs, resulted due to tool revolution and transverse, provides a plausible place for origination of cracks in the processed specimens [60], [61]. Also, it is interesting to note that, material consolidation can only be appropriately done if the material has been adequately plasticized, prior to the deposition [62]. Therefore, considerable fatigue life improvement can be obtained by a careful design of the FSW tool shoulder, resulting a quality weld or surface generation. In case of FSP, it is particularly required as it helps in obtaining ultra-fine grain structure in processed regions without changing the thickness of the sheet, which is a potential benefit to the superplastic forming industries.

Different researchers have contributed on shoulder geometry and reported their views, as G. Casalio et al. [63] studied the impact of the diameter of the tool shoulder on $3 \mathrm{~mm}$ thick aluminium plate and concluded that, microstructural zones and hardness profiles of the metals are governed by shoulder size. Sahu and Sukhomay et al. [64], identified the impact of shoulder diameter and plunging depth of the tool in FSW and concluded that, when other parameters were kept constant, an increase in the value of shoulder diameter, increases the mechanical properties of the material. Whereas, K. Ramanjayulu et al. [65] conducted a study 
on the role of different tool shoulder diameters, ranging from $12-24 \mathrm{~mm}$, and reported that the material flow driven by tool shoulder decreases with the increase of the tool shoulder size. Padmanaban et al. [66] selected a set combination of tool material, tool shoulder and tool pin profile for FSW of Magnesium alloy AZ31. They reported production of a defect-free joint with enhanced mechanical properties, with the use of a threaded pin profile tool of high carbon steel, as compared to other counterparts, having same $18 \mathrm{~mm}$ shoulder diameter, keeping D/d ratio above 3. Also, Malarvizhi et al. [67] reported the considerable influence of tool shoulder diameter on different mechanical properties of dissimilar AA6061 aluminium and AZ31magnesium alloys, through their experimentation. They fabricated joints by using tools of different shoulder diameters as, 12, 15, 18, 21, 24mm and stated that maximum tensile strength attained by shoulder diameter of $21 \mathrm{~mm}$, which was 3.5 times the plate thickness.

\subsection{Shoulder surface/profile}

As heat generation is caused by mutual rubbing of tool shoulder and material surface, the shoulder surface profile has a significant influence on the amount of heat generation. Also, shoulder surface profile, along with shoulder geometry, plays an important role in controlling the material flow, in addition to heat generation, grain refinement and improving surface microstructure. As stated in the equation 1, the amount of heat generation also depends on the effective value of the coefficient of friction, which can be varied by the variation of shoulder surface profile. Therefore, tool diameter is a deciding parameter for heat generation and plastic deformation of the stir zone, shoulder profile designs add more of friction and corresponding heat generation with same values of revolution of the tool. R S Mishra and Z.Y. Ma [30] showed 5 different types of tool shoulder geometries as given in figure 6.

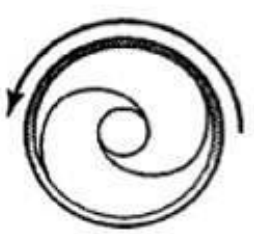

a. Scrolled

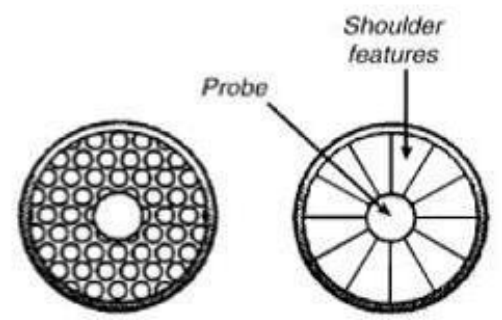

c. ridged

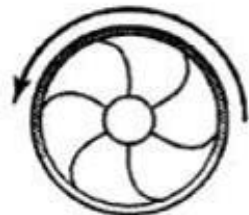

d. grooved

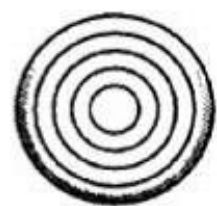

e. concentric

Fig. 6 Different Types Of Tool Shoulder Geometries

Scialpi et al. [17] use three different shoulder geometries (Figure 7) on $1.5 \mathrm{~mm}$ thick 6082 Aluminium alloy sheet. The tool used was with a Cavity and a fillet, which resulted in a higher longitudinal and traverse strength of joint and also the best crown on thin sheets.
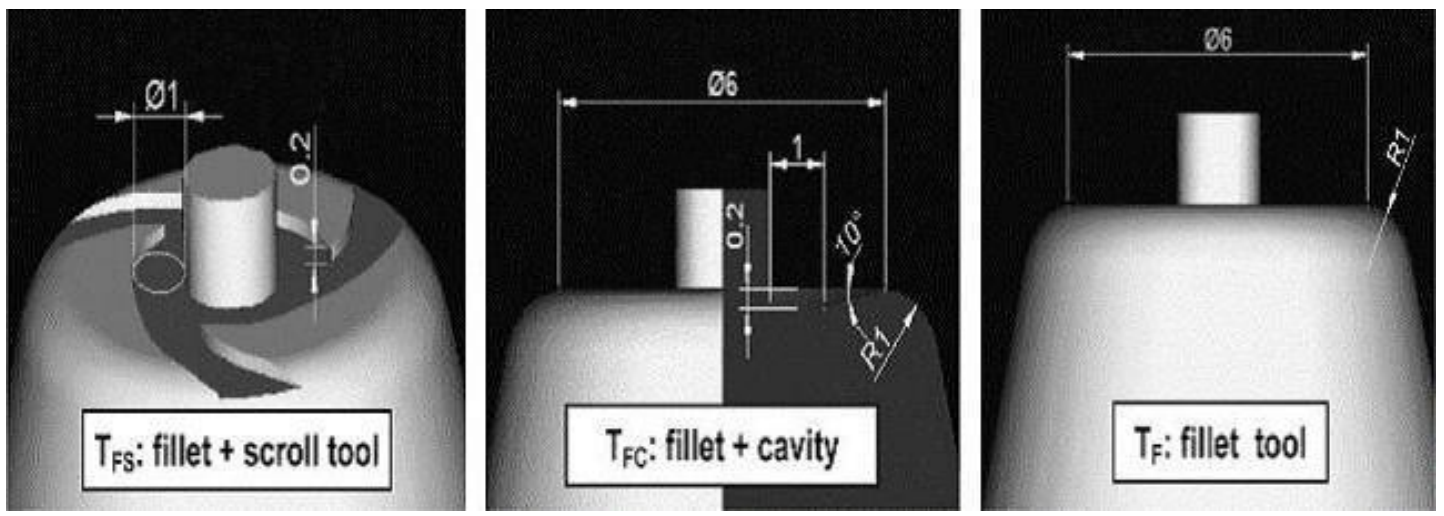

Fig. 7 Three Different Shoulder Geometries tried by Scialpi et al. [17] 
Giorgi et al. [34] investigated the impact of three different shoulder geometries on the performance of FSW joints, focused on fatigue behavior and residual stress generation. But they were unable to provide clear results on the effect of tool geometry due to lower values of transversal residual stress. Later, Galvao et al. [58], tried with three tool geometries (Figure 8) and reported that scrolled geometry provides the most suitable metal flow and refined grain structure in the stir zone of the weld.

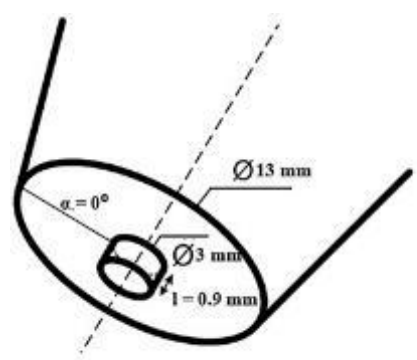

(a) Flat tool

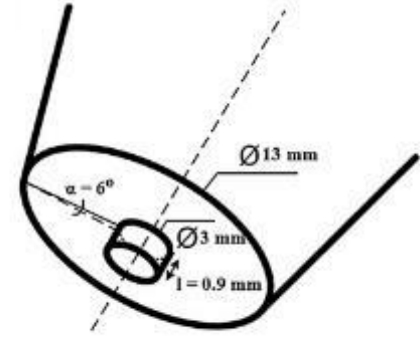

(b) Conical concave tool

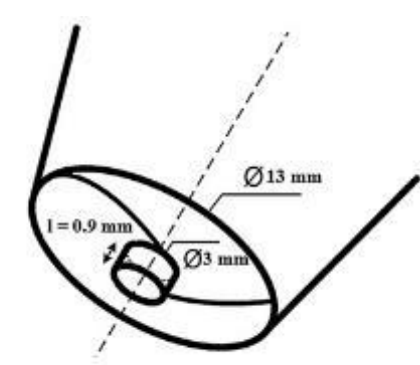

(c) Scrolled tool

Fig. 8 Three Tool Geometries as tried by Giorgi et al. [34]

The flow of plasticized material takes place in two different modes as, shoulder oriented and pin oriented, as stated by Kumar et al. [24]. It has been observed that material derived by the tool shoulder actually forges against the advance side of the base material, followed by the pin is driven material. This happens by eliminating the boundary layers in between the pin is driven and shoulder driven materials. The shoulder profile is a considerable factor as a bulk material transfer under shoulder is governed by the shoulder diameter and profile.

Hirasawa S. et al. [68], experimented with two types of shoulder shapes convex and concave along with different pin geometries as shown in figure $9(a, b)$.

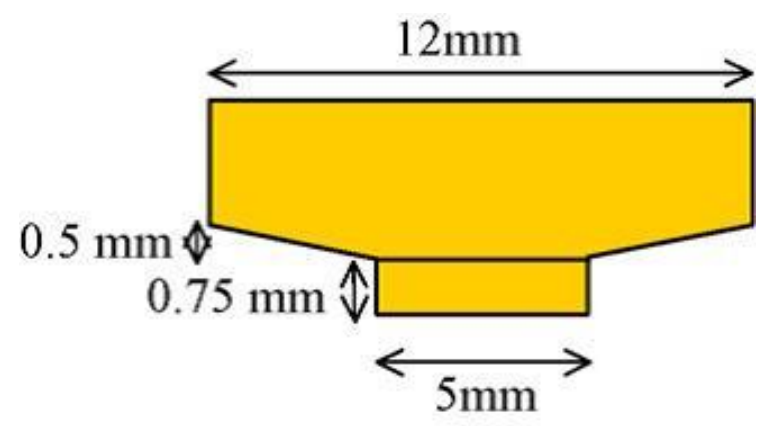

Fig. 9 (a)

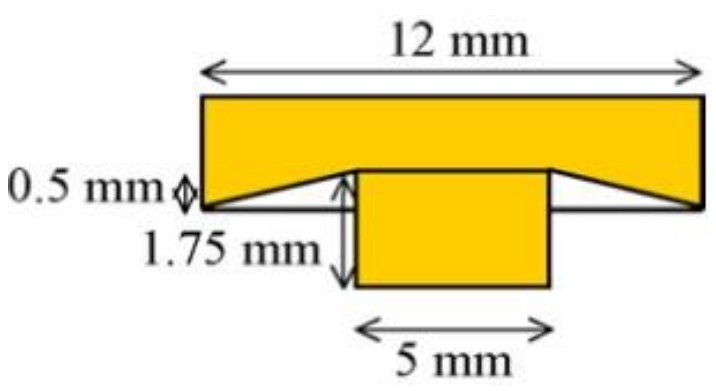

Fig. 9 (b)

In case of concave shoulder shape the material flow is confined around the pin and mostly driven inwards, which ensure improved mixing due to strong material flow. Generation of a hook type structure has been observed in such cases, as when the tool is plunged in the material initially and before the shoulder contact, the plasticized material is pushed upwards by the pin. This upward thrusting material and occupies the space in between shoulder and the workpiece before coming in contact with the shoulder. This results in lower axial loads due to a lesser amount of extruded material as compared to flat and convex shoulder profiles. In case of convex shoulder profile, the material in contact is more, which results in higher axial loads, as expressed by Badrinarayan et al. [69] and they analytically proved nullification of any 'hook' formation in the weld region generated due to this type of tool geometry. The above statements make shoulder profile a dominant parameter to be considered for the process efficiency and quality. 


\subsection{Pin Geometry}

Many studies regarding the impact of pin and pin and have established it as a prominent parameter to be considered for generation of different mechanical properties due to the refinement of grains in processed material. Elangovan et al. [18], reported the pin profile influence along with rotation speed of tools, in FSP of AA2219 aluminium alloy and they found that square pin profiled tool has produced a zero defect friction stir processed zone irrespective of rotational speeds. Similarly, the impact of pin geometry in case of FSW on an aluminium alloy has been studied by Zhao et al. [16]. They reported that profile of the pin significantly governs the flow of the locally plasticized material and a quality weld can be attained by using screw threaded profiles with a taper. In addition to above, Boz et al. [29] investigated the behavior of threaded tool pin profile and its corresponding thread pitches, while experimenting with friction welding of Aluminium alloy. They reported observance of a drilling action rather than stirring, in case of larger pitched threads. Such thread forces the plasticized material outward in the form of semi-molten material chips, which was not desired. On the other hand, best bonding with defect-free joints was obtained from low pitch threaded tools.

Also, Elongovan K et al. [52] stated that flow of material has been principally affected by the geometry of tool pin profile, its dimensions, and process parameters. They reported that a cavity has been observed produced by the insertion of the tool and shape of the cavity depends upon the pin profile. Also, the plasticized material flow under the tool, from advancing side to retreating side, is found governed by two different modes i.e. shoulder driven and the pin is driven. Kumar et al. [24], reported that bulk flow of material is derived from the tool shoulder, whereas rotation of pin adds layers of material flow. The material flow driven by tool shoulder forges the material from retreating side to the trailing side, whereas the pin driven material, which is just below the tool shoulder driven material, is deposited by one layer over the other and solidifies. The material is compelled to whirl as per the rotational speed of the tool and has to move transversely with respect to tool transition speed to produce a zero defect weld zone.

From the above-mentioned studies, it can be said that tool pin profile is a principal and deciding factor for the quality of the processing, its geometry, impact on localized heating and stirring action and the resulting homogeneous mixing. It is considered as primary source of deformation and secondary source of heat generation in the stir zone as stated by Radisavljevic et al. [70].

Many researchers have dedicated their studies to different profiles of the pin and their influences on property generation. Pin designs become important as the material flow in the region under the pin is considerably influenced by the geometrical parameters and profile of pin itself. The ideal design of the pin should constraint maximum material within the stirring zone. Thomas et al. [45] developed pin profiles like Whorl type, MX Tri flute type, A-skew type of pin profiles, for special purposes and stated that each pin profile has its own impact on material flow and other properties such as effective orbital forging of the material, higher mixing of materials and reinforcements and size determination of TMAZ and HAZ regions.

Many researchers stated the threaded pin profiles are preferred for adequately refined grains, homogeneous distribution of particulates and corresponding property generation. Azizieh et al. [71] considered the impact of adding threads and flutes to a columnar pin profile on the microstructure and corresponding hardness of AZ31/A12O3 Nanocomposite fabricated by FSP. Faraji et al. [72], observed the excellent distribution of $\mathrm{Al}_{2} \mathrm{O}_{3}$ particles in the matrix of AZ91 Magnesium alloy with the use of a square pin profile tool with continuously pulsating stirring action. Bahrami et al. [62], studied five different profiles of the pin (figure 
10) and proved that threaded tapered pin resulted in the homogeneous distribution of particulates within the stir zone. But in case of triangular pin profile specimens, they observed some clusters generation in the processed material. Also, improper distribution of particulates has been observed, in case of the four-flute cylindrical specimen with a severe accumulation of reinforcement particulates. In context with mechanical properties, all specimens produced by other profiles have shown almost identical results with negligible variations, however, the triangular pin profile specimen resulted in the highest ultimate tensile strength.
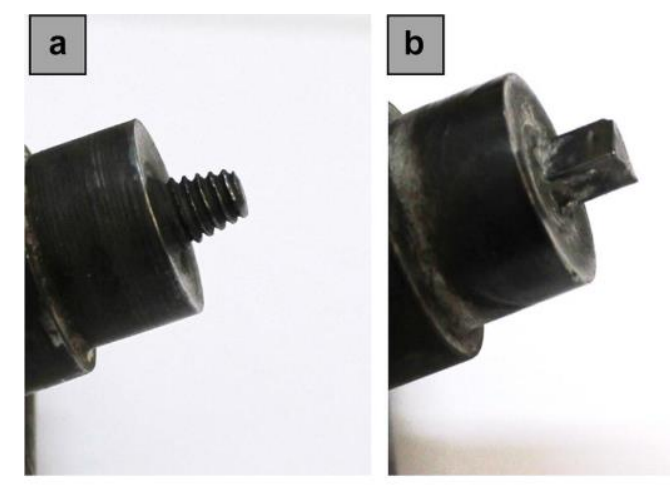

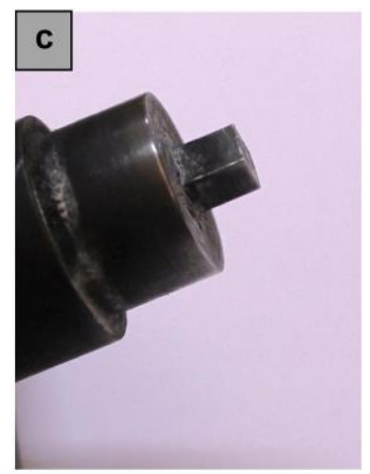

\section{d}

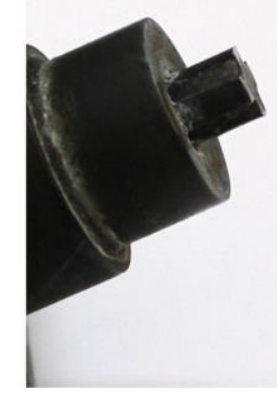

e

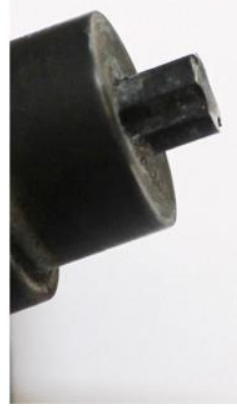

Fig. 10 Five Different Profiles Of The Pin Studied by Bahrami Et Al. [62]

M. Ilangovan et al. [73] studied tools with three different pin profiles (Figure 11) and discussed their influence on microhardness and tensile properties the material processed. The pin profiles used for the experimentation, as shown in figure 11, as straight cylindrical (STC), threaded cylindrical (THC) and tapered cylindrical (TAC), were used to fabricate the joints for welding of rolled plates of AA 5086-O and AA 6061-T6 aluminium alloys.

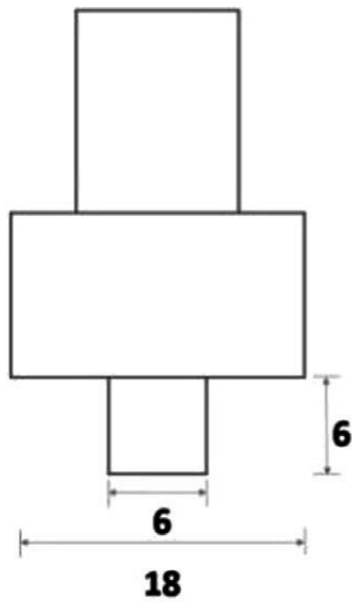

STC

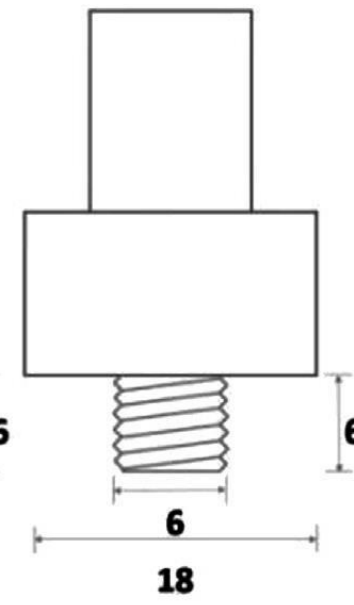

THC

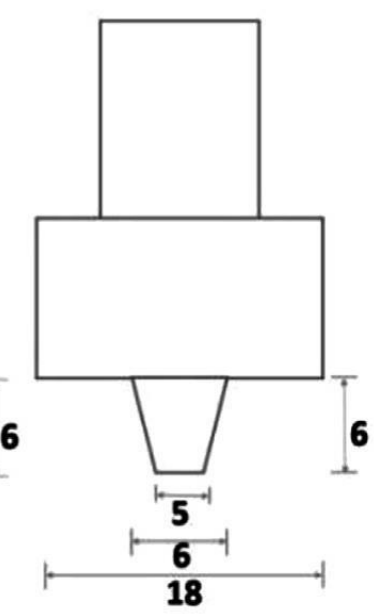

TAC

Fig. 11 Tools With Three Different Pin Profiles Studied By M. Ilangovan Et Al. [73] 
They reported the development of defect-free joints by threaded and tapered cylindrical pin profiles. Also, results recorded were almost similar with a little variation of $5 \%$. However, they concluded that, for superior performances of joints, threaded cylindrical pin profile is preferred, rather than tapered cylindrical pin profile. Padmanaban et al. [66], used five different tool profiles for their study such as straight cylindrical, tapered cylindrical, threaded cylindrical, triangular and square and with three shoulder diameters i.e. $15 \mathrm{~mm}, 18 \mathrm{~mm}, 21$ $\mathrm{mm}$. They also selected five different tool materials for their experimentation as mild steel, stainless steel, armor steel, high carbon steel, high-speed steel and reported that by using threaded pin profile, resulted in joints exhibited higher hardness in the nugget zone, as compared to other counterparts, as shown in Graph 1. The D/d ratio, when kept more than 3.0 (shoulder diameter $18 \mathrm{~mm}$ ) exhibited more hardness in the stir zone as shown in Graph 2. High carbon steel tool resulted in more hardness in the stir zone as compared to other tool materials, as shown in Graph 3.
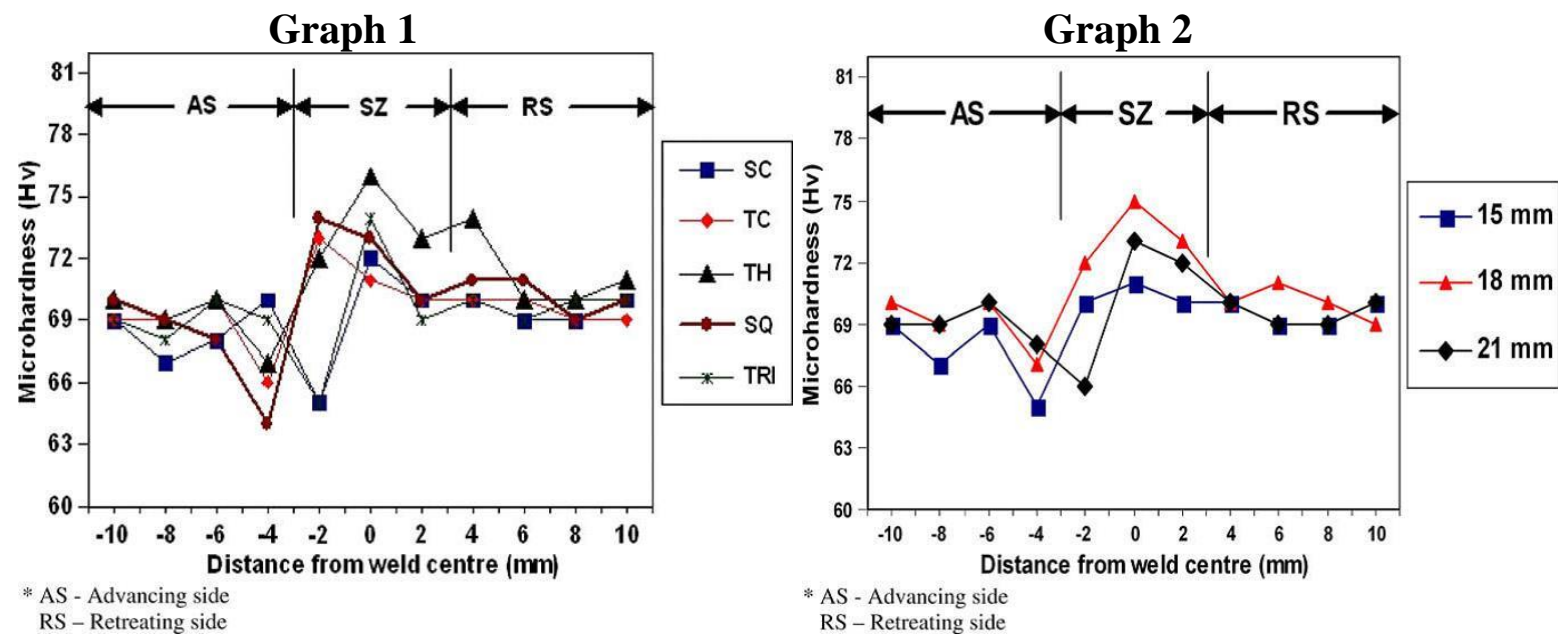

Tool pin profile impact on hardness. Shoulder diameter impact on hardness

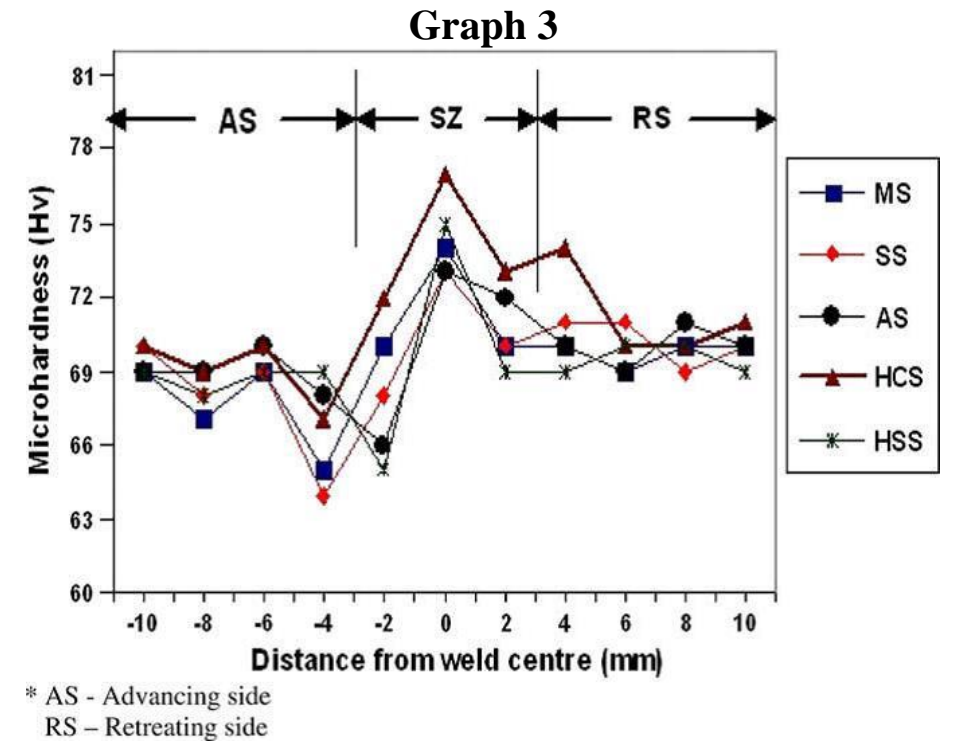

Tool materials impact on hardness

They reported the development of a tunnel defect in the stir zone by using straight cylindrical pin profile, which provides an initial site for the failure of the material. On the other hand, higher tensile strength was observed by using threaded pin profile, due to intense stirring and 
heat generation relative to the taper pin profile. The dynamic recrystallization of the stir zone renders fine recrystallized equiaxed grains which contribute to the enhancement of mechanical properties.

In a latest report by Rezaee Hajideh et al. [74],evaluated effect of four different tool pin profiles such as square (S), threaded cylindrical (TC), triangular (T) and straight cylindrical (SC) pin shape, on tools made up of $\mathrm{H} 13$ hot work tool steel. Other geometrical aspects as shoulder diameter $17 \mathrm{~mm}$ and pin diameter inscribed diameter of $10 \mathrm{~mm}$ are kept same (as shown in Figure 12).

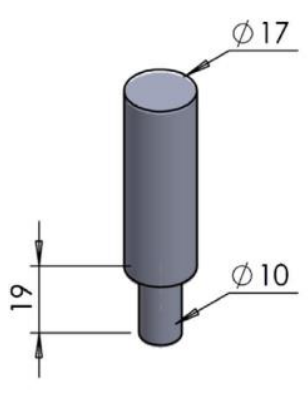

unit: $\mathrm{mm}$

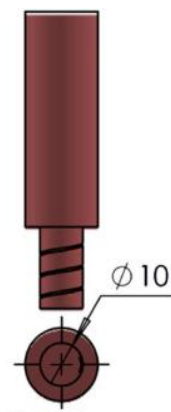

pitch:5

(TC)

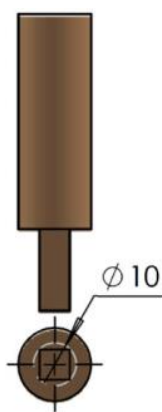

(S)

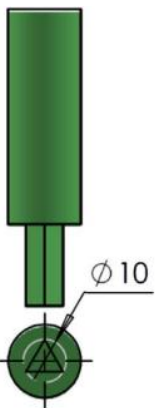

(T)

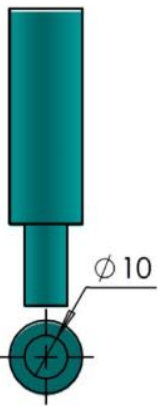

(SC)

Fig. 12

They recorded that the threaded cylindrical tool profiles have resulted in higher strengths than other tool profiles, due to adequate stirring action. Severe mixing of the plasticized material has been noted by using the tool of squared and triangular pin profiles, but on joint strength front, specimens prepared by threaded cylindrical tool was higher which represents the recommendable performance of this pin profile. Graphical representation of enhancement of mechanical properties is represented in graphs 4,5 and 6 , as per their study. The values of Traverse speed and rotational speed as $12.5 \mathrm{~mm} / \mathrm{min}$ and $900 \mathrm{rpm}$ respectively, were kept constant. Graph 4, 5 and 6 (data referred from [73])

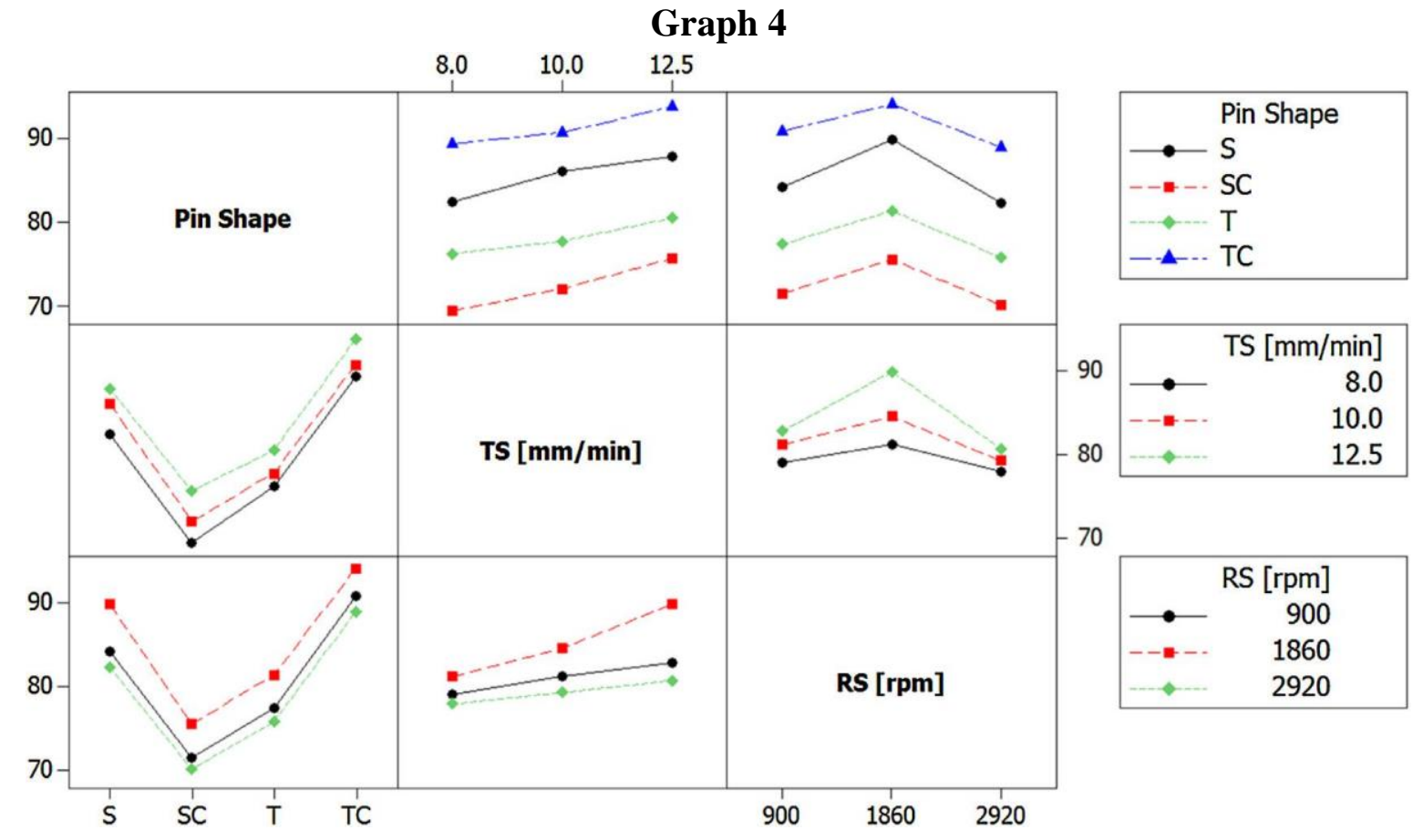



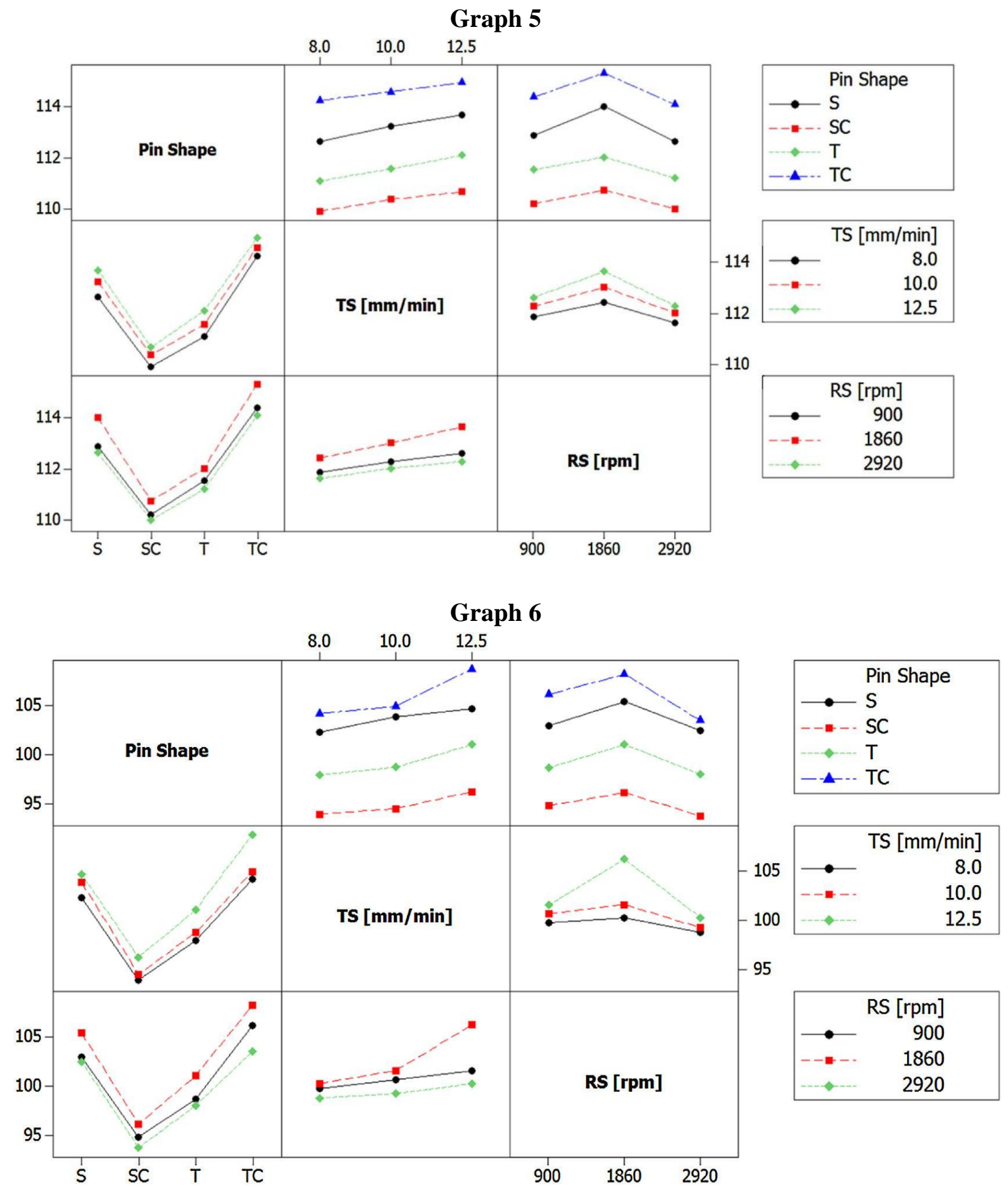

The flow pattern of the material around the pin, in case of threaded pin tools, plays a considerable role in generating material microstructure and subsequent mechanical properties of the processed material. The orientation of the threads on pin governs the flow of the material below and around the pin. Colligan et al. [75] reported material flow pattern of a lefthand screw threaded pin tool, rotating in clockwise direction. The material was observed to be forced downwards by the thread profile and deposited as a nugget. Also, Guerra et al. [76], and Zhao et al. [16], experimented with a threaded pin with right-hand thread orientation and rotating in an anticlockwise direction and reported defect free joints in welding. It is also observed that a combined effect of thread orientation and rotation of the pin tool enhances the 
extra downward force and generation of heat. This is found beneficial in accelerating the flow of plasticized material and ensures the improved material properties and bonding. While using a right-hand screw threaded pin with clockwise rotation, evident defects were observed at the bottom of the welded joints, as reported by Cao et al. [77]. These observations and analysis of results indicate that flow of material during stir processing and welding is a function of pin tool thread and direction of rotation of the tool. Chowdhury S.M. et al. [78], experimented with Left-hand thread (LHT) pin and right-hand thread (RHT)pin, rotating in a clockwise direction with a rotating speed of $1000 \mathrm{rpm}$ and $2000 \mathrm{rpm}$ and transition speed of $10 \mathrm{~mm} / \mathrm{s}$ and $30 \mathrm{~m} / \mathrm{s}$. It has been observed that the flow of materials reversed in the case of RHT pin tools and LHT pin tools. The material which has been softened being very close to RHT pin tools rises up towards the tool shoulder, whereas, the softened material in the vicinity of the LHT pin tool flows downwards, as shown in Figure 13 (a \& b).
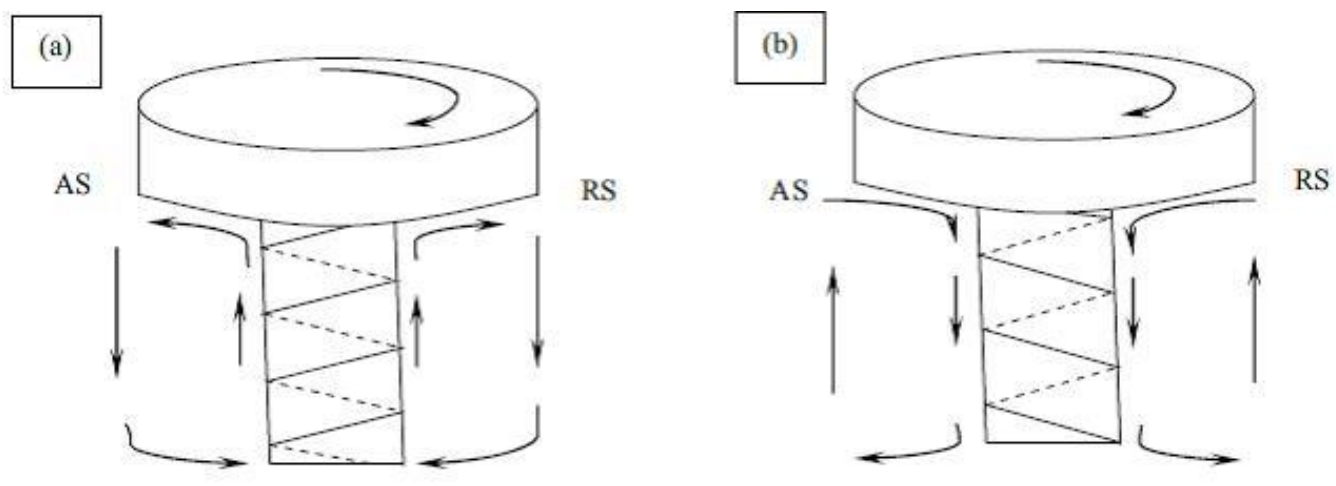

Fig.13 (a) RHT; (b) LHT and AS: tool advancing side and RS: tool retreating side

Also, it has been stated that to obtain a quality joint, the threaded pin must be rotated in a direction so that the threads must divert the material downwards, such as LHT pin rotated in a clockwise direction and RHT pin in an anticlockwise direction. Whereas RHT pin tool (Figure $11 \mathrm{a}$ ), rotating in the clockwise rotation and there would be chances of incidence of probable porosity or lack-of-bonding types of defects. There are two possible causes of the defects generated, firstly, due to sticking of plasticized material moving upwards and sticking to the tool shoulder and pin itself, which will be reducing the further deviation of material at the base of the weld, as stated by Seidel et al. [79]. Secondly, due to the formation of the extensive temperature gradient in between the top surface, which is in contact with the tool shoulder and bottom surface, which is in contact with the clamping support. The material flow near the bottom surface will be subjected to more flow resistance when it moves upwards, as reported by Fairman $\mathrm{M}$ et al. [80]. Therefore, it is more probable to get a porous and lack of bonding types of defects at the bottom of the weld, which can be easily observed from the fractured surface during a fatigue test, as shown in Figure 14 (a), which used RHT pin profile with clockwise rotation and no such defect has been observed in Figure 14 (b), made by LHT pin profile with same clockwise rotation of the tool.

The above is well supported by Kadian et al. [81] by their report that, in case of threaded pin geometries, the movement of softened material is observed as fast flowing, specially near the shoulder region of the pin where the viscosity was considerably low due to elevated temperature. This low viscosity softened material is compelled to move upwards along the threaded pin pitch which acted as channels for this movement. Also, in case of grooved pin profile tools, a higher movement of the material has been observed but found incapable to move the material near the pin tip region due to higher viscosity of the material, resulting in an increase in probability of defect formation in that region. 

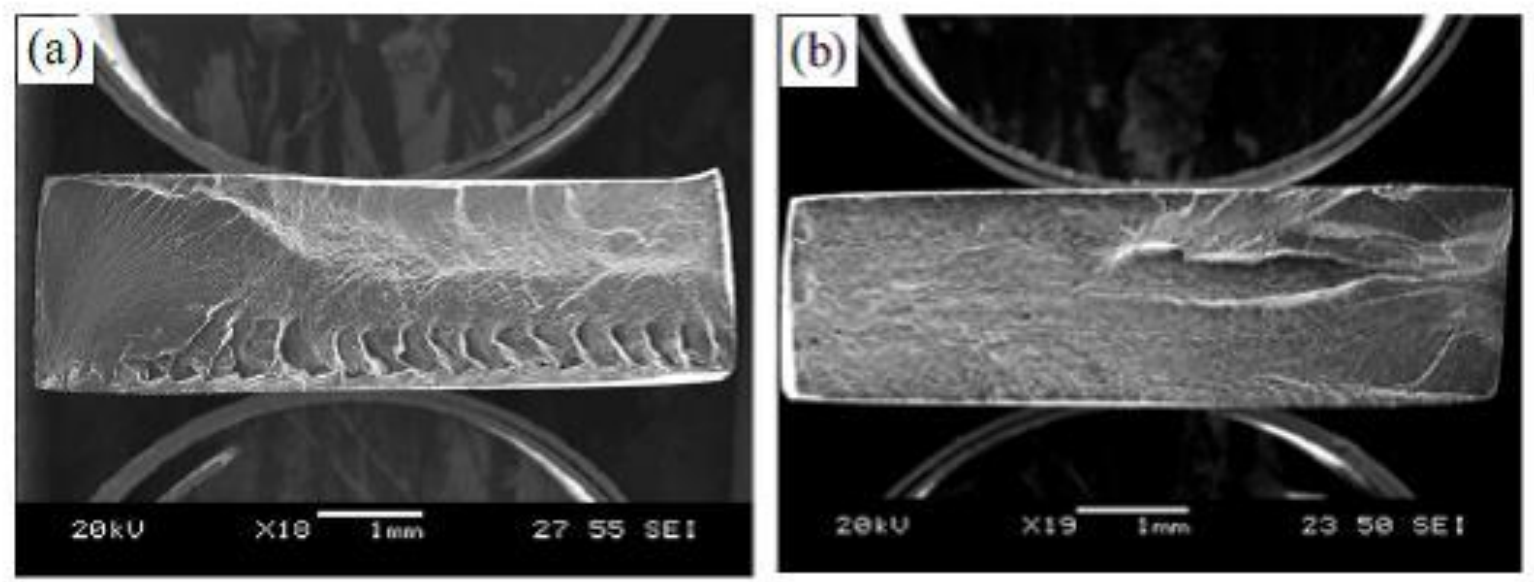

Fig. 14 SEM images of samples after fatigue test, (a) RHT pin tool,

(b) LHT Pin Tool, both rotating in a clockwise direction

In addition to above, the special innovative design of pin also had been reported and studied for better results. Donald H. Wykes invented and patented a moving pin type of tool in 1997 with Patent Number: 5,697,544, in the US, as shown in figure 18. This patented design of the tool the moveable pin is completely retracted relative to the tool shank is such a way that the tool shank may engage with the work piece while the pin may not. The tool may be of a variable diameter providing a variable volume cavity. therefore the insertion of the pin into the work piece the variable width shank expands and increases the circumference of the shoulder and the volume of the cavity. The length of the pin within the volume cavity ensures a good surface material flow along with a high weld quality using the stir friction welding process.

$$
\text { U.S. Patent Dec } 16,1597 \quad \text { Sheet } 3 \text { of } 4 \quad 5,697,544
$$

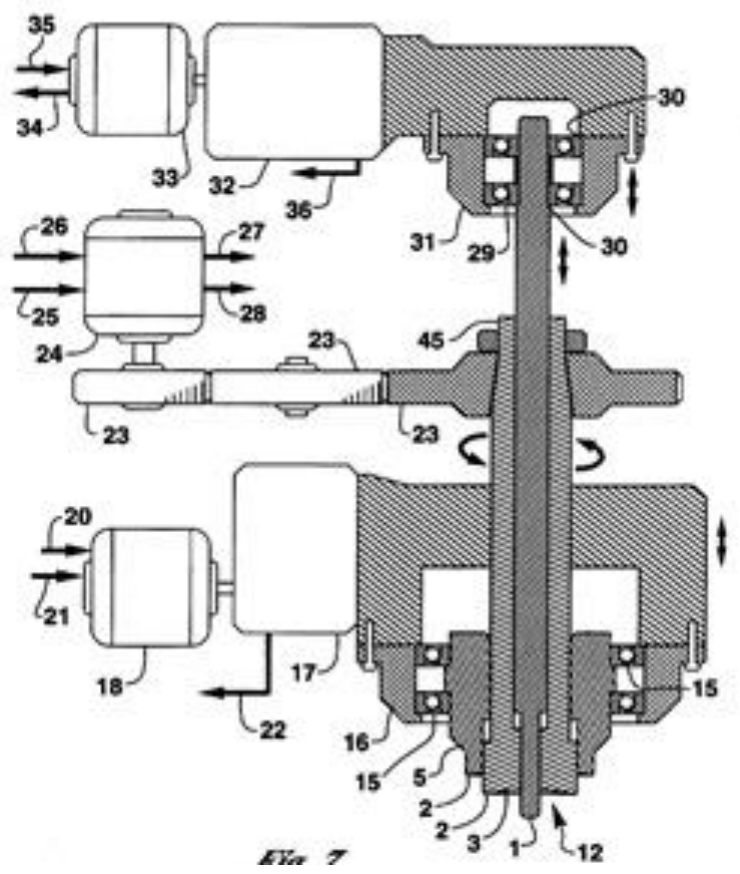

Fig. 15 
From above it can be said that the tool pin profile has a prevailing impact in the stirring region, both thermally and mechanically, and govern the quality generation in the processed material. Studies on tool pin profile also established that the movement of the softened material is largely governed by tool shoulder, whereas material movement in the lateral and upward directions is governed due to pin profile. Also, different geometries of the pin profile have their own impacts on different regions of material revolution in the stirring zone and largely affected by the tool rotation and corresponding heat generation.

\subsection{Tilt Angle}

It has been observed that a small offset angle, as $2^{0}$ to $4^{0}$ were given to tool pin from the main axis (Figure 16), can generate more stable joints [82]. It has been observed that, while using minimum rotational speeds, the samples processed without the tool tilt angle faced a serious problem of decreased tensile properties due to lower downward forging force. But adding a small value to tilt angle, considerable property enhancement in the material processed has been seen [83].

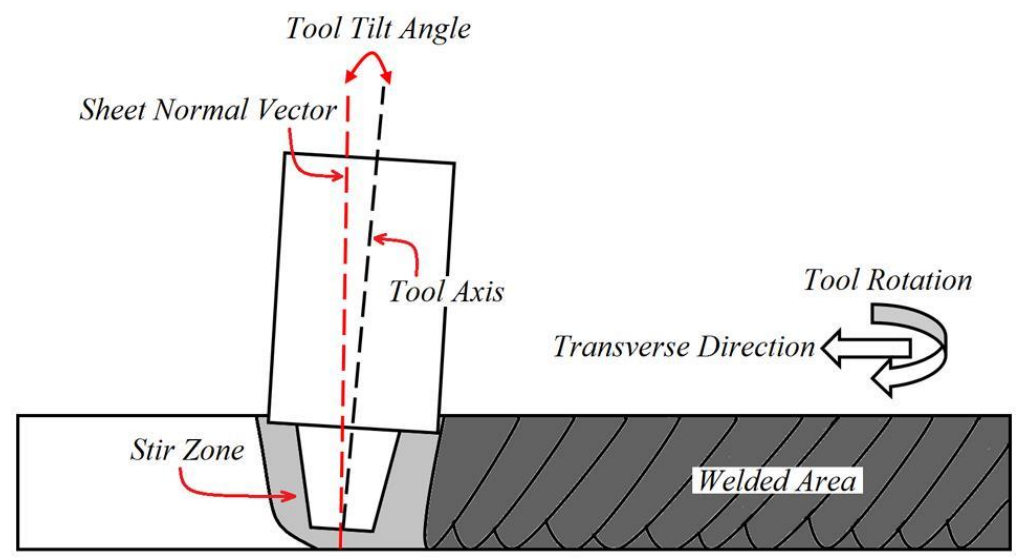

Fig. 16 Small tilt Angle (display)

Due to transverse of the tool in a direction, the plasticized material tends to forge into the cavity developed by the tool pin behind the retreating side (RS) to advancing side (AS). This gap is directly proportional to the value of the tilt angle, i.e. lager the tilt angle more will be the gap. Any positive value of the tilt angle promotes the gap and supports the escape of plasticized material from tool shoulder base, but larger values of the angle result in the development of voids in the work material due to the escape of more material than desired as stated by Seighalani et al. [84]. They showed the specimens in support of above as Fig.17 (a $\&$ b), where less material can be observed in the retreating side of the tool movement, which is collected from the advancing side. Also, for fewer values of the tilt angle and consequent inadequate forging will be resulting in improper welding and homogeneous mixing.

A smaller value of tilt angle facilitates the movement of the material, but larger values can cause a discontinuity in the processed material and render voids formation. This emphasizes on requirement determining an optimum value of the tilt angle, based on the material to be processed and processing parameters opted.

Different studies reported different values of tilt angle chosen as per the type of workpiece material and tool material. Chen et al. [85], investigated that with the same welding parameters, channel defect is has been resulted by using tilt angle values below $1.5^{\circ}$ and above $4.5^{\circ}$. They also stated that the value of tilt angle influences the heat generation and positions of the defect generation in a welding area. Kato et al.[86], also reported defects in the weld zone, when the tilt angle is kept at $0^{\circ}$ and above $3^{\circ}$. Also, Z. Barlas et al. [87], reported that tilt angle of $2^{\circ}$ produces a defect-free weld. Moneer et al. [88], reported that 
optimum results were achieved with a tool tilt angle of $2^{\circ}$ and with a tool offset of $1 \mathrm{~mm}$. Most recently, Mehta et al. (2016) [82] studied the influence of tilt angle on dissimilar material systems. Keeping rotational speed and welding speed as constant, only tilt angle was varied from $0^{\circ}$ to $4^{\circ}$ with an interval of $1^{\circ}$. Defect-free welds in Copper and Aluminium are attained by using tool tilt angles $2^{\circ}, 3^{\circ}$, and $4^{\circ}$. Also, maximum hardness and tensile strength were attained by a tilt angle of $4^{\circ}$, whereas the macro hardness was found increasing as the tilt angle increases from $0^{\circ}$ to $4^{\circ}$. Seighalani et al. [84] studied the macro-structural analysis of the welded joints of pure titanium with a simple cylindrical WC pin and a W shoulder, via FSW in presence of compressed air jet as a coolant, Argon as a shielding gas. They reported that for the above conditions, tool tilt angle of $1^{\circ}$ leads to a defect-free weld joint. Elyasi et al. [89], investigated the effects of tool tilt angle on the friction stir welding of aluminium to the steel. They selected tool tilt angles as $1^{\circ}, 2^{\circ}$ and $3^{\circ}$ for the process, while the other process parameters such as tool rotational speed, traveling speed, tool offset and plunge depth was kept constant. They reported that, with the increase of tool tilt angle value, the interaction between two metals and axial force increases and cause more frictional heat generation. Also, maximum tensile strength was observed by using tool tilt angle of $2^{\circ}$.
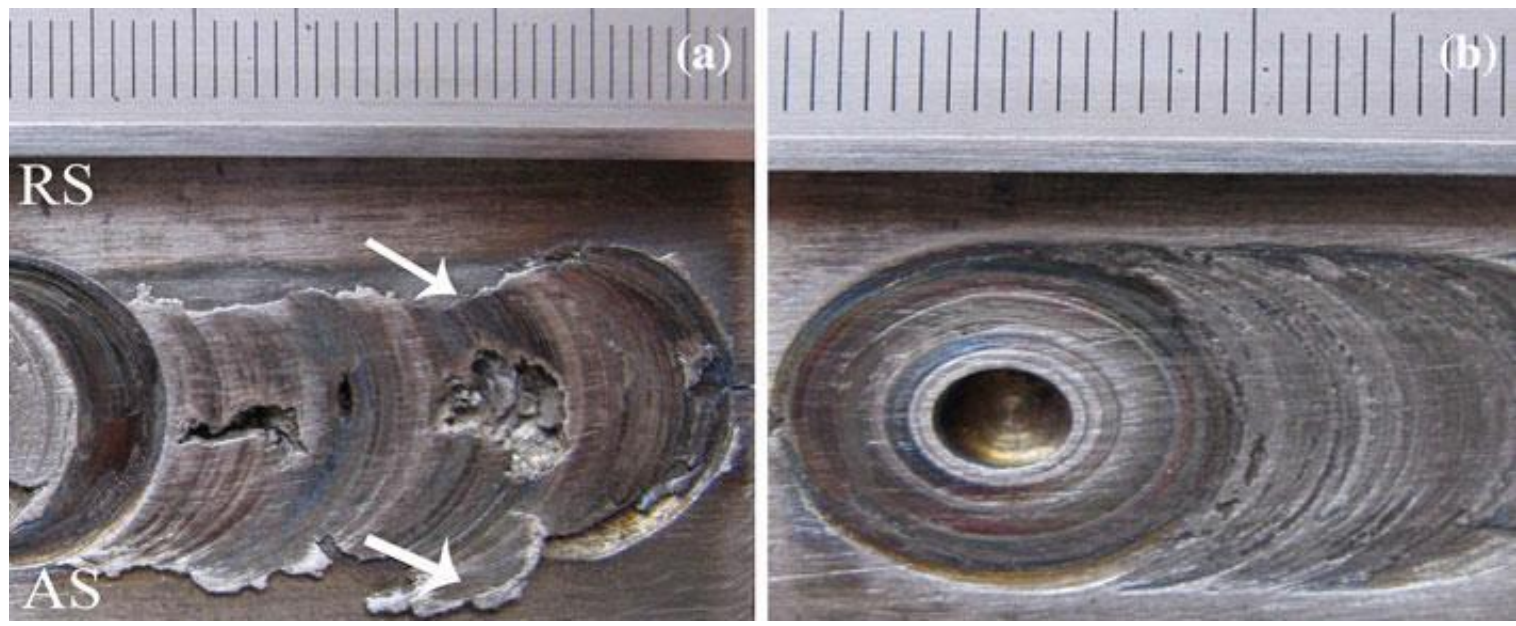

Fig. 17 a) Voids formed in the joint area (tilt angle $3^{\circ}$ ); b) Joint form (tilt angle $1^{\circ}$ ) [99]

From the above consolidation of studies, it is clear that smaller positive values contribute to the enhancement of properties with the defect-free material, whereas larger values generate voids and other defects in the resulting material. The value of the tilt angle depends on the type of the tool material and material to be processed. Therefore, an optimum tool tilt angle value is to be determined to inculcate different mechanical properties in the work material.

\section{Tool wear and failure}

There are two different modes of tool degradation, as deformation and wear. Deformation of tools is indicated by the change in geometrical parameters and shape of the tools, whereas wear corresponds to a loss of mass from the tool surface, as stated by Gan et al. [43].

Different tool materials have different wear characteristics. Thompson and Babu [41], carried out an experiment with three compositions of tungsten-based tool materials for their FSW experimentation. They alloyed highly refractory elements such as lanthanum oxide, rhenium, and hafnium in varying proportions in the tool material and reported an increased tool life for the tool materials embedded with hafnium (10\%) and rhenium (20\%) in the base tungsten matrix. It is as compared to tool materials of tungsten added with $1 \% \mathrm{La}_{2} \mathrm{O}_{3}$ and $25 \%$. Also, in tool degradation studies of tungsten carbide (WC), FSW tool material was carried out by Siddiquee et al. [40]. The study was conducted on $2.95 \mathrm{~mm}$ thick AISI304 
stainless steel sheets, and they reported degradation of the FSW tool due to the modes of plastic deformation and tool wear, due to intensive process loads at high temperatures. Also, bulging of tool shoulder due to plastic deformation of tool rendered an increase in tool pin taper angle. Tool wear was also observed in the base of the pin, i.e. on the bottom face of the pin, caused due to diffusion. Different tool attrition mechanisms on tool shoulder and pin surface are observed. In addition to above, Wang et al. [90], performed a similar study while FSW of Ti-6Al-4V titanium alloy using tools constituted with $\mathrm{W}-1.1 \% \mathrm{La}_{2} \mathrm{O}_{3}$ and two different grades of WC-Co based materials. They investigated tool wear and mass loss by techniques of microscopy and tool profile photography and reported tool degradation resulted due to plastic deformation in case of $\mathrm{W}-1.1 \% \mathrm{La}_{2} \mathrm{O}_{3}$ tool and can be reduced by increasing the pin diameter.

Many scholars have contributed their works on degradation of the tools, especially while working with high melting temperature materials [4], [21], [91] - [93] and stated that wear and deformation of the tool contribute in more of heat generation than desired and act reversely on to the property generation. In both, the cases of friction stirring, i.e. FSW and FSP, the tool wear is caused either by mechanical damage or due to chemical affinity inbetween tool and workpiece material. As they share the same phenomenon of working, the deformation is related to variation in rates of stress and strains, which is resulted due to hightemperature generation during FSW/P. Hence sustainability of tool material is required to withstand high frictional and resultant forces imposed on the pin during initial plunge stage [90].

Sorensen and Stahl [94] also have stated that increase in plate thickness generates requirement of a large force in case of AA6061 Aluminium processing. Gan et al. [43] mentioned sever tool wear and deformation of pin profile during processing of L80 steel. They found higher yield strength of the order of $400 \mathrm{MPa}$, at $1000{ }^{\circ} \mathrm{C}$, and recommended the use of tools made up of Re alloyes with $\mathrm{w}-25 \%$, for the purpose. [27], also studied the generation of the severe impact of forces on the Friction stirring tool corresponding to an increase in plate thickness and strength of workpiece alloy. Arora et al. [95] have stated pin of the tool as the weaker section in the complete tool, even structurally. Higher temperatures and mechanical stresses generated during the process can damage the pin considerably. Also while processing composites the tool wear is observed. Enhanced tool wear is noted by Prado et al. [83] while welding speed is increased in case of AA6061-T6 + 20Vol\%Al2O3 metal matrix composite, with a tool made up of $\mathrm{H} 13$ steel. They demonstrated the wear variation with the speed as in Figure 18, with a constant rotation and varied speed of transverse. Liu et al. [96] experimented on AC4A $+30 \% \mathrm{SiC}$ metal matrix composite, with a tool of WC-Co alloy and considerable distortion of the tool is noted. Figure 19, shows the wear of the tool in each step of the process. It is clearly visible that, threads disappear after first welding from the root area of the pin (Figure $19 \mathrm{~b}$ ). Also, minimum wear is observed in upper half of the pin, and maximum wear is noted in lower half of the pin (Fig 19 b-h). Complete elimination of the threads exhibits considerable wear after the last welding.

Although different mentioned studies are in support of using harder tool materials to delay the tool failure in case of friction stirring processes and welding. Many researchers have contributed in analyzing the tool wear by different mathematical models and calculated the deviations in peak temperatures, traverse forces, and torques, rendered on the tool while in use. These deviations are difficult to monitor and examine in real-time due to the inherent nature of the process. A few studies are quoted for reference in the case such as Manvatkar et al. [97], implied artificial neural network based models to assess the increase in tool traverse force and torque with the rise in welding speed in FSW of AA7075. Frigaard et al. [59], computed for highest temperature values during welding of Aluminium and Zinc Alloys. 
Later, Khandkar et al. [98] calculated the similar values for Al- Cu alloys. Trimble et al. [99] estimated the forces required during Traverse of the tool along with the value of torque required while processing AA2024 Aluminium, but they have not commented on mechanical stress issues in relation to the process.
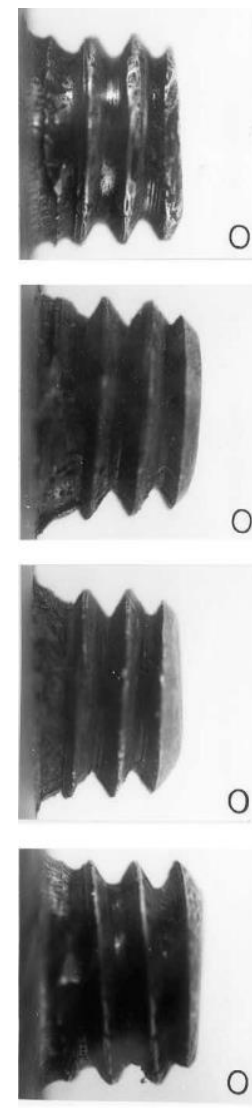

$\mathrm{O}$
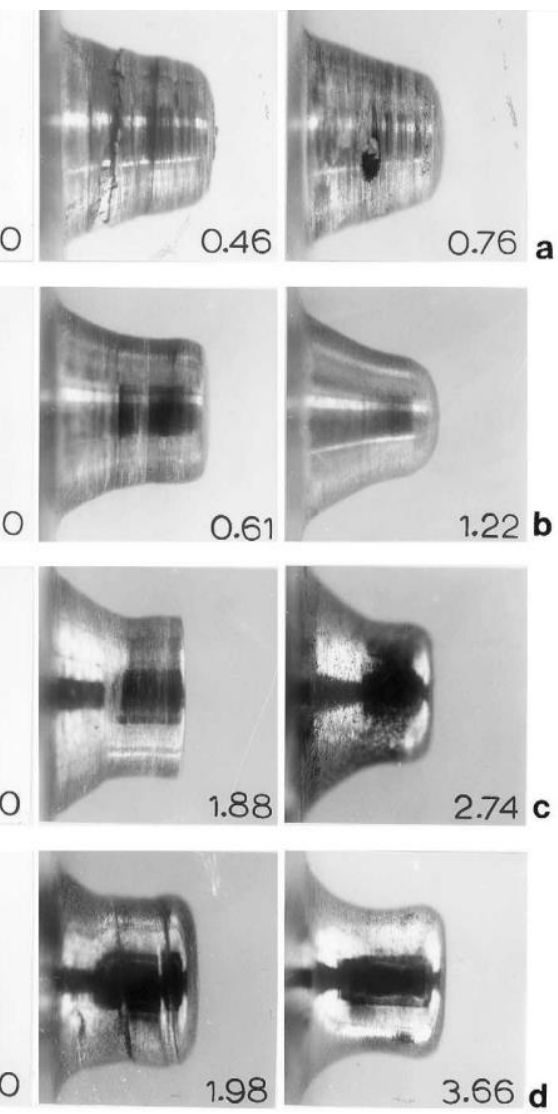

Fig. 18 Tool Pin wear at constant tool rotation of $1000 \mathrm{rpm}$ and weld traverse distances noted in meters.
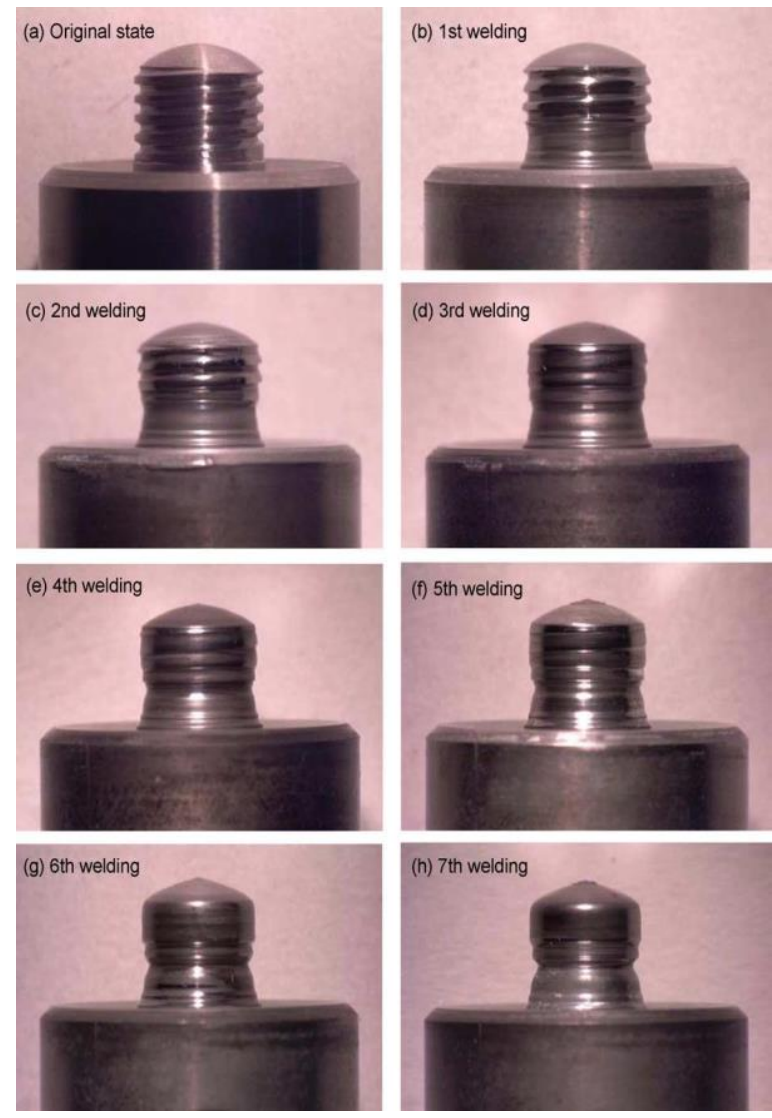

Fig. 19 Appearance of the threaded tool after each FSW experiment.
(a) $T_{-} 1$ mm s_1;
(b) T_ 3 mm s_1;
(c) T_6 mm s_1;
(d) $T_{-} 9$ mm s_1.

Debroy et al. [100] and De et al. [101] examined the process with both mathematical and analytical models and computed the values for peak temperature, traverse force, torque and stresses, required for processing of different alloys. Debroy et al. [100], explained the context of assessing the mechanical stresses with the help of durability factor. They stated that, durability factor is a ratio of limiting stress of tool material to the maximum resultant shear stress experienced by tool pin, for any FSW condition. The shear yield strength of the tool material is considered as limiting stress, in the above consideration. Also, Su et al. [102], demonstrated the impact of tool pin profile on the peak temperature in case of AA2024 Aluminium. Almost all the studies are performed considering plate thicknesses less than $6 \mathrm{~mm}$, therefore there is a scope for the temperature evaluation and mechanical stresses observed by the tool in case of thicker plates.

Recently, Buchibabu V. et al. [103], studied two different aluminium alloys of plate thicknesses and different strengths for evaluating transverse force, torque and mechanical stresses generated on the tool. Three dimensional analysis of heat transfer has been studied by them at steady state and reported a considerable reduction of durability factor while 
processing thick plates at high welding speeds. This was resulted due to elevated values of torque and traverses force, along with resultant maximum shear stresses and lower peak temperatures. They concluded that, for a particular welding condition, larger the work piece strength higher will be the transverse force, which will be resulting maximum shear stress and lower durability.

Therefore, less than unity value of tool durability factor proves higher resultant stresses on tool pin than the shear strength of the tool material. In addition to above, S. Kumar et al. [104], has experimented FSP with ultrasonic assistance on Aluminium alloy and reported that the roughness of the surface increases with the increase of processing speed. Also, lesser speeds result in a better surface quality and adequate mixing of the reinforcement. Therefore it can be said that lower processing speeds contribute to the enhancement of surface quality and corresponding more durability of the tool.

\section{Morphological Analysis in context with mechanical properties}

Y. Huang et al. [57], experimented with a hollow Direct Friction Stir Processing (DFSP) tool and analyzed with the SEM images (Figure 20 a \& b) that, the reinforcement particles dispersed in a scattered and homogenous way in the SZ of processed AZ31, and the grain boundary was pinned by the Silicon carbide particles, as shown Figure 21 (b), which is improved as compared to conventional tools. Figure 20 (a \& b), exhibits the SEM images of the composite layer of processed AZ31 with the Si C particles and Figure 21 shows the microhardness profile of the Traverse section in as received AZ31, pure processed AZ31, and AZ31 reinforced with Si C particulates.

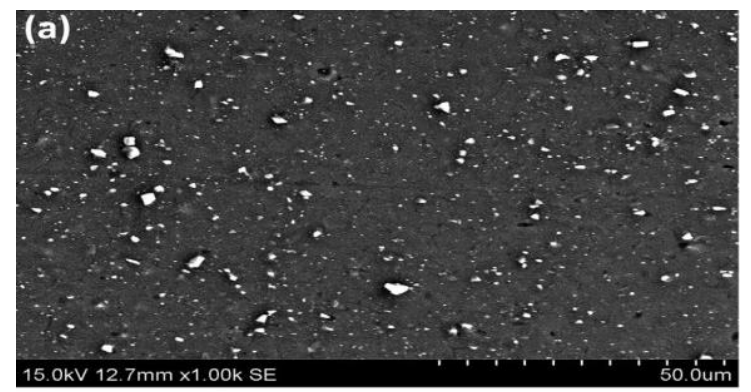

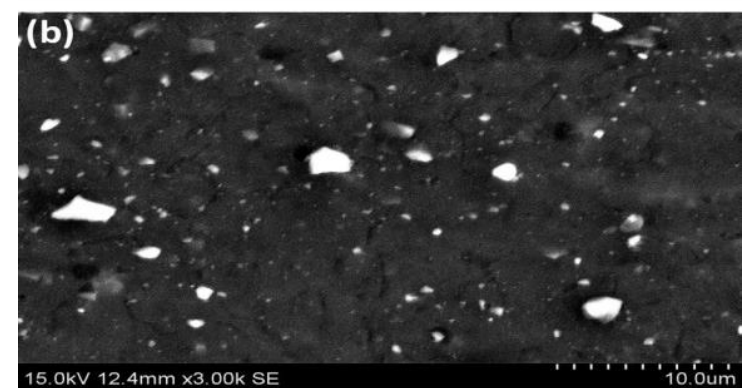

Fig. 20

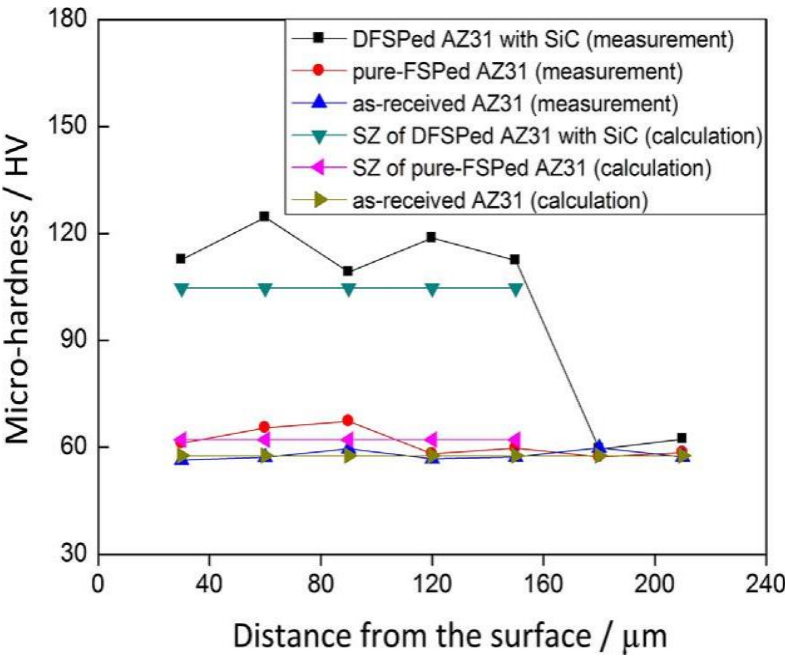

Fig. 21

Bahrami et al. [62], experimented the process of friction stir welding (FSW) using five geometrically different pin tools, as shown in Figure 10. They indicated the material flow pattern around the pin, depending upon the geometry of the pin and different for different geometries. While deployed for reinforcement purposes, the flow of material plays an important role as it governs the particulates dispersion in the processing zone. Hence it can be stated that pin geometry controls the particle distribution pattern.

Microstructural evaluation using SEM, as shown in Figure 22, revealed sections of more clustered and free particle regions in the stir zone (SZ). By using threaded tapered pin tool profile, most uniform particle distribution was recorded. But the severe accumulation of 
reinforcements is revealed in the SZ, while processed with four-flute cylindrical pin tool profile. Also, lowest microhardness is been reported by the same. Whereas, highest microhardness is noted in case of threaded tapered tool pin profile.
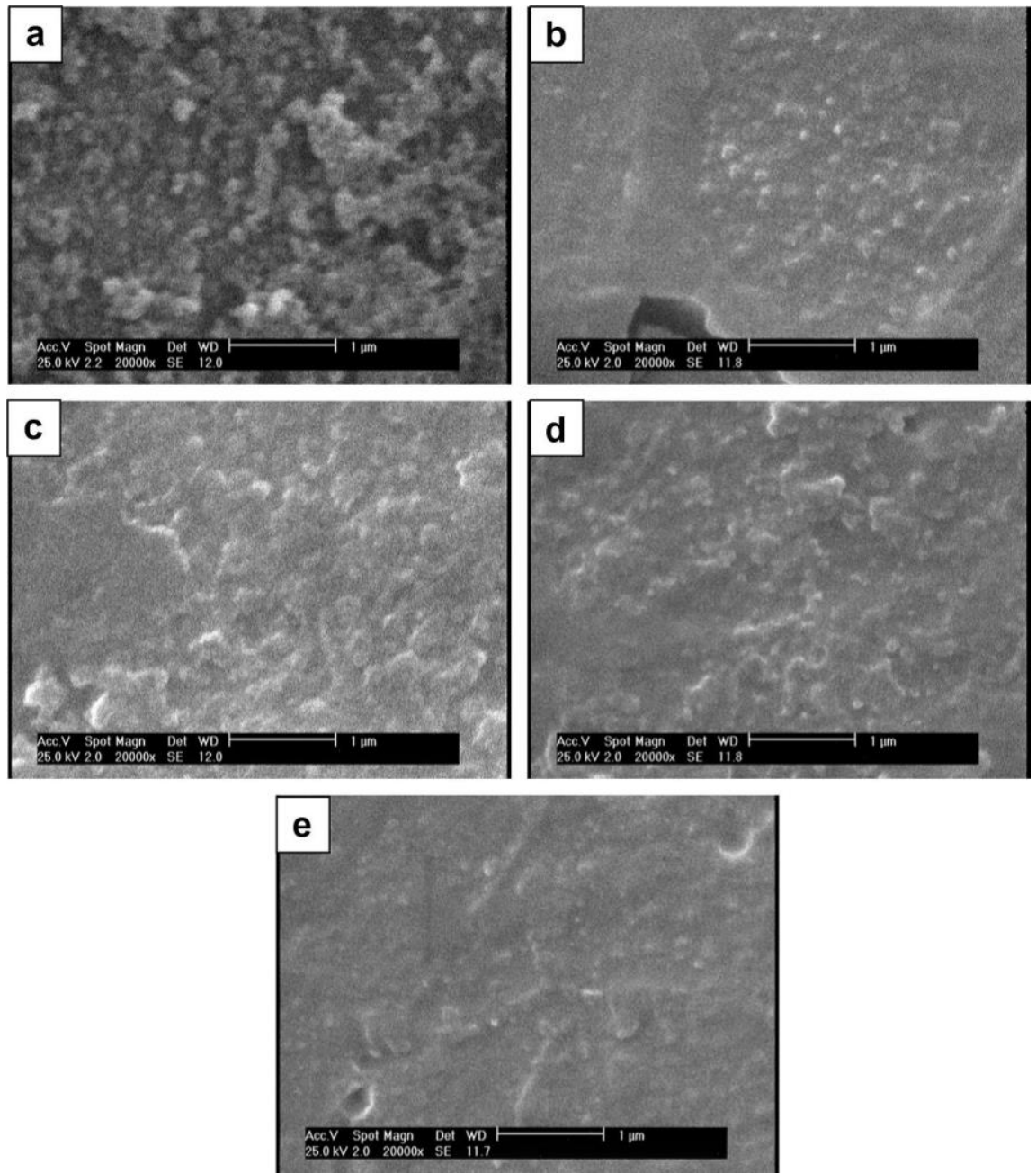

Fig. 22 Dispersion of SiC nano-particles in SZ of specimen friction stir welded with:

(a) TT (threaded tapered) (b) T ( triangular) (c) S (square) (d) FFS (four-flute square) and (e) FFC ( four-flute cylindrical)

As Padmanaban et al. [66] used five different profiles of pin in their experimentation, as discussed earlier in this paper, they concluded that, when threaded tool pin profile is used to fabricate a joint, it results in higher hardness in the stir zone, as recorded, in comparison with other tool pin profiles. High carbon steel was used as a tool material with shoulder diameter of $18 \mathrm{~mm}$. The joints nugget region was of finer grain structures with more number of subgrains, as compared to other profiles (Fig. 23c). Correspondingly, the joints made with D/d ratio 3.0, exhibited finer grains as shown in Fig. 25 (b) as compared to other counterparts. Also, Fig. 24 (d) exhibits finer grains with tool material high carbon steel, as compared to other tool materials.

As, M. Ilangovan et al. [73] have studied the impact of three different tool pin profiles on tensile properties and microhardness of the material processed. They used pin profiles, as shown in figure 11, i.e. straight cylindrical (STC), threaded cylindrical (THC) and tapered cylindrical (TAC) for processing rolled plates of AA 5086-O and AA 6061-T6 aluminium alloys. In figure 26, Fractography of notched tensile specimens is presented [72]. As it is 
known that strength of welding of dissimilar metals depends upon the presence of defect-free stir zone along with coursing grain structure in the stir zone.

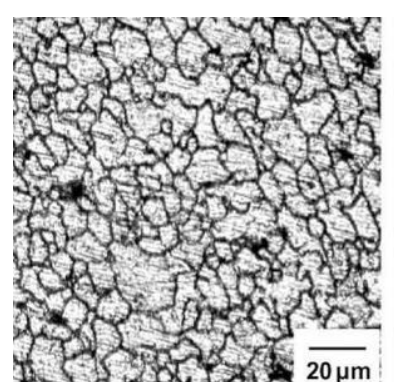

(a) Straight cylindrical

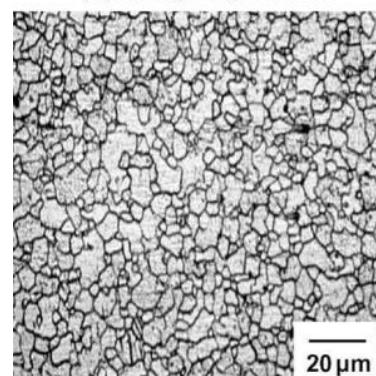

(c) Threaded cylindrical

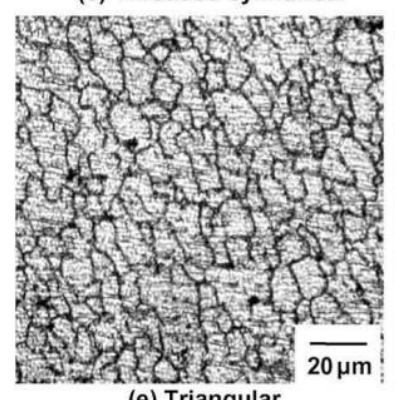

(e) Triangular

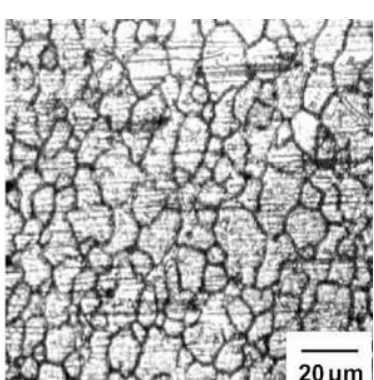

(b) Taper cylindrical

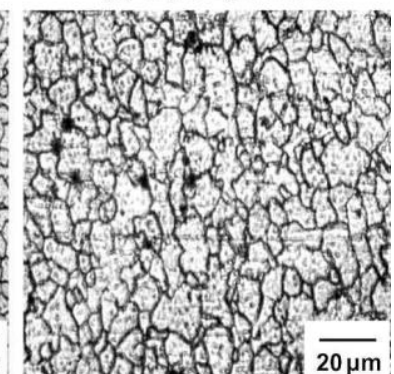

(d) Square

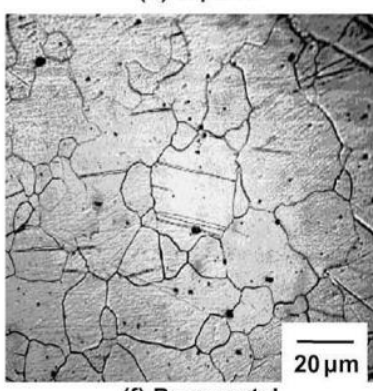

(f) Base meta

Fig. 23 Tool pin profile impact on stir zone microstructure.

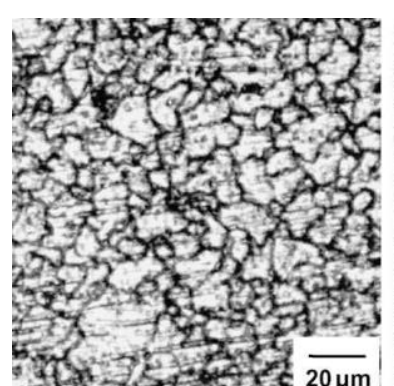

(a) Mild steel

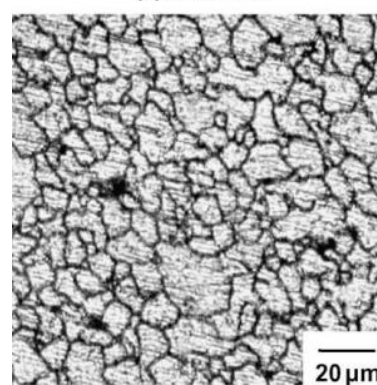

(c) Armour steel

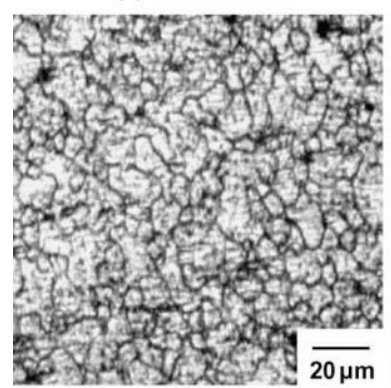

(e) HSS

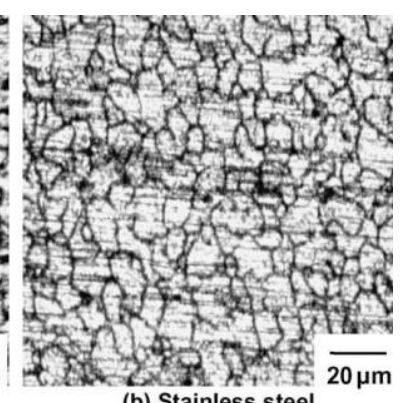

(b) Stainless steel

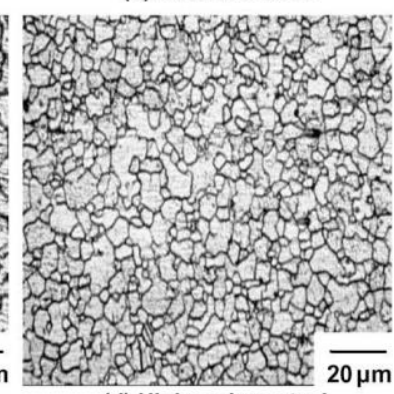

(d) High carbon steel

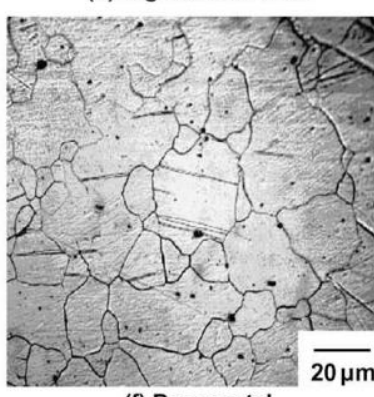

(f) Base metal

Fig. 24 Tool materials impact on stir zone microstructure.

The figure shows, while using a straight cylindrical tool (STC), lower tensile strength is reported due to the presence of defective stir zone. Presence of tunnel defect in the advancing side represents the site of failure initiation. Whereas, in case of threaded pin profile, a higher tensile strength was observed due to the presence of stable precipitates, which contribute to the strengthening of the specimen. In case of a threaded cylindrical pin, the precipitate is partially dissolved in the stir zone, also, a few unstable precipitates tend to transform into stable precipitates. These precipitates are covered by dislocations which object the dislocation motion during tensile loading, which strengthens the material in stir zone. Also, the mixing of dissimilar materials is facilitated more easily by the use of threaded pin profile than any other profile in the study, as a meshing of the metals increases, which improves the mechanical locking between the materials. This again contributes to the improvement of strength in case of threaded pin profile. 


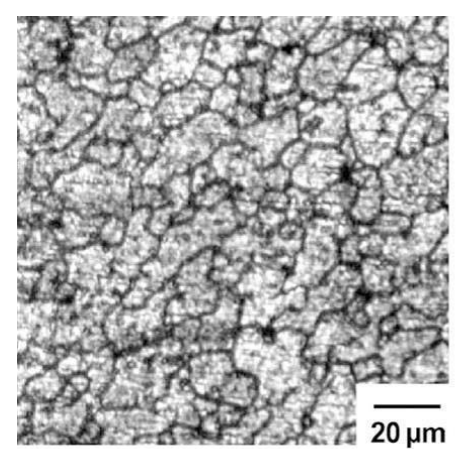

(a) $\mathrm{D} / \mathrm{d}=\mathbf{2 . 5}$

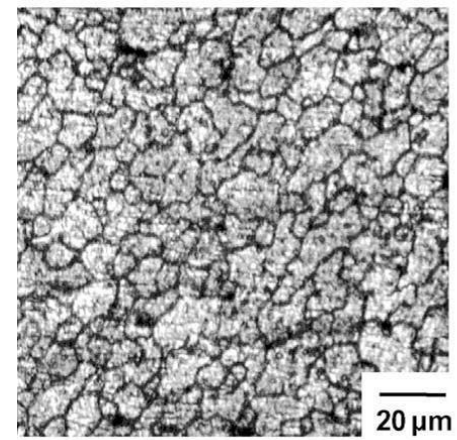

(c) $\mathrm{D} / \mathrm{d}=3.5$

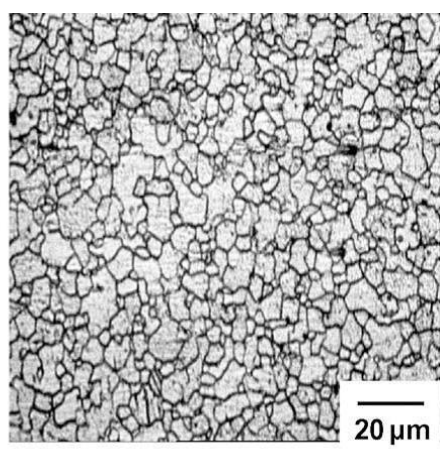

(b) $D / d=3.0$

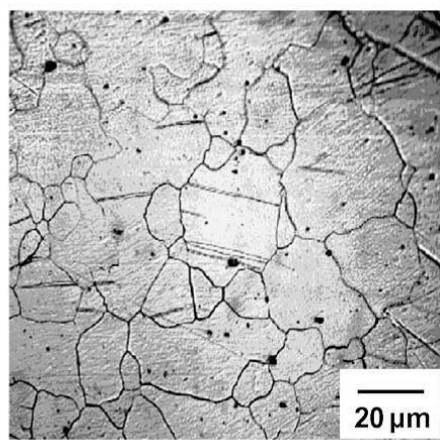

(d) Basemeta

Fig. 25 Tool shoulder diameter impact on stir zone microstructure.

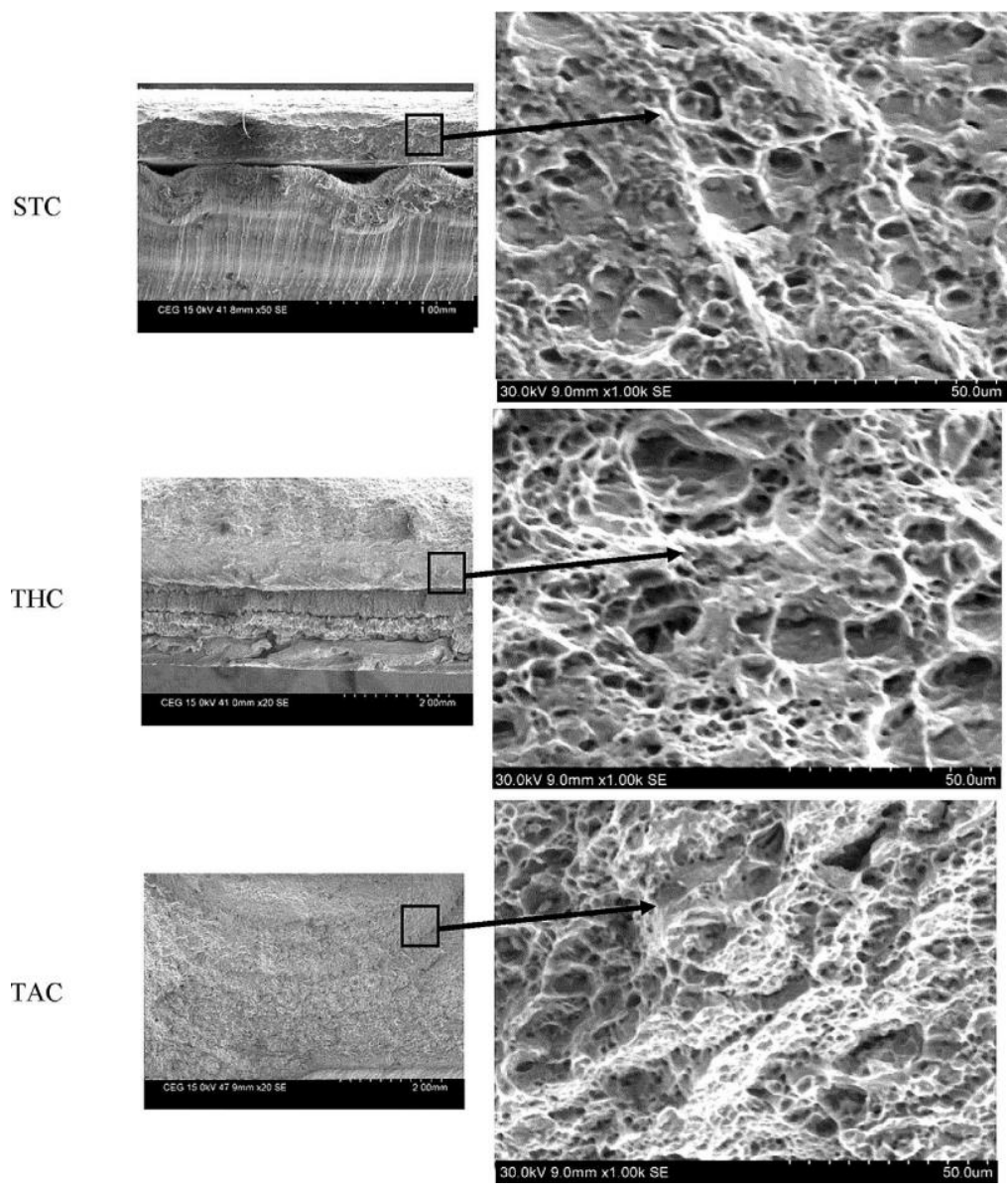

Fig. 26 


\section{CONCLUSIONS}

- The geometrical parameters of friction stir welding and processing tool have a considerable impact on the quality of the resulting material.

- Tool shoulder is found responsible for adequate heat generation for dynamic recrystallization in the stir zone and shoulder profile a dominant parameter to be considered for the process efficiency and quality. Concave shaped profile of tool shoulder confines the plasticized material in the stir zone and enhances better mixing possibilities.

- Also, the dimensions of shoulder diameter may be kept a minimum 3 times to the thickness of the plates to be processed, to obtain good results.

- Pin profiles are the most important criteria to be considered as it governs the refinement of the stir zone and responsible for dynamic recrystallization. Threaded cylindrical tool profile with left-hand threads is better than other profiles and thread orientation when the tool is rotated in clockwise direction.

- An optimum tool tilt angle value is to be determined to inculcate different mechanical properties in the work material. As smaller positive values of tilt angle restrict the process itself and larger values generate voids in the resulting material. Therefore, the value of the tilt angle is to be optimized for the process, considering, type of the tool material and material to be processed.

- Tool wear can be moderated by calculating the durability factor for the tool. As durability factor less than unity depicts a higher resultant stress on the tool pin than the shear strength of the tool material. Therefore, an optimum value is needed to be obtained for a process, depending upon the type of material to be processed, tool material, the transverse force deployed for the process and axial load to be applied.

\section{REFERENCES}

[1] Ahmadkhaniha, D., Heydarzadeh Sohi, M., Zarei-Hanzaki, A. "Optimisation of friction stir processing parameters to produce sound and fine grain layers in pure magnesium", Sci. Technol. Weld. Join. 19 (3), pp. 235 - 241, 2014.

[2] Mahoney, M. W. "Friction stir welding and processing", Mater. Sci. Eng. R Reports, 50 $(1-2)$, p. 360, 2007.

[3] Chang, C. I., Du, X. H., Huang, J. C. “Achieving ultrafine grain size in Mg-Al-Zn alloy by friction stir processing”, Scr. Mater. 57 (3), pp. 209 - 212, 2007.

[4] Zhang, Y., Sato, Y. S., Kokawa, H., Park, S. H. C., Hirano, S. "Stir zone microstructure of commercial purity titanium friction stir welded using pcBN tool", Mater. Sci. Eng. A, 488 (1-2), pp. 25 - 30, 2008.

[5] McNelley, T. R., Swaminathan, S., Su, J. Q. "Recrystallization mechanisms during friction stir welding/processing of aluminum alloys", Scr. Mater. 58 (5), pp. 349 - 354, 2008.

[6] Ma, Z. Y. "Friction Stir Processing Technology: A Review", Metall. Mater. Trans. A 39 (3), pp. $642-658,2008$.

[7] Ma, Z. Y., Liu, F. C., Mishra, R. S. "Superplastic deformation mechanism of an ultrafine-grained aluminum alloy produced by friction stir processing", Acta Mater 58 (14), pp. 4693 - 4704, 2010. 
[8] Ma, Z. Y., Mishra, R. S., Mahoney, M. W. "Superplastic deformation behaviour of friction stir processed 7075Al alloy", Acta Mater. 50, pp. 4419 - 4430, 2002.

[9] Charit, I., Mishra, R. S. "High strain rate superplasticity in a commercial 2024 Al alloy via friction stir processing”, Mater. Sci. Eng. A 359 (1-2), pp. 290 - 296, 2003.

[10] Hsu, C. J., Kao, P. W., Ho, N. J., Chang, C. Y. P. Y. "Al-Al3Ti nanocomposites produced in situ by friction stir processing", Acta Mater. 54 (19), pp. 5241 - 5249, 2006.

[11] Ke, L., Huang, C., Xing, L., Huang, K. "Al - Ni intermetallic composites produced in situ by friction stir processing”, J. Alloys Compd. 503 (2), pp. 494 - 499, 2010.

[12] Hsu, C. J., Kao, P. W., Ho, N. J. "Ultrafine-grained Al-Al2Cu composite produced in situ by friction stir processing", Scr. Mater. 53 (3), pp. 341 - 345, 2005.

[13] Lim, D. K., Shibayanagi, T., Gerlich, A. P. "Synthesis of multi-walled CNT reinforced aluminium alloy composite via friction stir processing", Mater. Sci. Eng. A 507 (1-2), pp. $194-199,2009$.

[14] Dixit, M., Newkirk, J. W., Mishra, R. S. "Properties of friction stir-processed Al 1100NiTi composite”, Scr. Mater. 56 (6), pp. 541 - 544, 2007.

[15] Barmouz, M., Asadi, P., Besharati Givi, M. K., Taherishargh, M. "Investigation of mechanical properties of $\mathrm{Cu} / \mathrm{SiC}$ composite fabricated by FSP: Effect of SiC particles' size and volume fraction", Mater. Sci. Eng. A 528 (3), pp. 1740 - 1749, 2011.

[16] Zhao, Y. H., Lin, S. B., Wu, L., Qu, F. X. "The influence of pin geometry on bonding and mechanical properties in friction stir weld $2014 \mathrm{Al}$ alloy", Mater. Lett. 59 (23), pp. $2948-2952,2005$.

[17] Scialpi, A., De Filippis, L. A. C., Cavaliere, P. "Influence of shoulder geometry on microstructure and mechanical properties of friction stir welded 6082 aluminium alloy", Materials \& Design 28, pp. 1124 - 1129, 2007.

[18] Elangovan, K., Balasubramanian, V. "Influences of tool pin profile and tool shoulder diameter on the formation of friction stir processing zone in AA6061 aluminium alloy," Mater. Des. 29, pp. 362 - 373, 2008.

[19] Arora, A., De, A., Debroy, T. "Toward optimum friction stir welding tool shoulder diameter", Scr. Mater. 64 (1), pp. 9 - 12, 2011.

[20] Krasnowski, K., Hamilton, C., Dymek, S. "Influence of the tool shape and weld configuration on microstructure and mechanical properties of the Al 6082 alloy FSW joints", Arch. Civ. Mech. Eng. 15 (1), pp. 133 - 141, 2015.

[21] Das, J., Rao, G. A., Pabi, S. K., Sankaranarayana, M., Nandy, T. K. "Thermomechanical processing, microstructure and tensile properties of a tungsten heavy alloy," Mater. Sci. Eng. A 613, pp. 48 - 59, 2014.

[22] Ghosh, M., Kumar, K., Mishra, R. S. "Analysis of microstructural evolution during friction stir welding of ultrahigh-strength steel”, Scr. Mater. 63 (8), pp. 851 - 854, 2010.

[23] Najafi, M., Nasiri, A. M., Kokabi, A. H. "Microstructure and Hardness of Friction Stir Processed AZ31 with SiC", International Journal of Modern Physics B 22, pp. 2879 2885, 2008.

[24] Kumar, K., Kailas, S. V. "The role of friction stir welding tool on material flow and weld formation”, Mater. Sci. Eng. A 485 (1-2), pp. 367 - 374, 2008. 
[25] Nandan, R., Debroy, T., Bhadeshia, H. K. D. H. "Recent advances in friction-stir welding - Process, weldment structure and properties", Progress in Materials Science 53, pp. $980-1023,2008$.

[26] Scutelnicu, E. "Fundamentals of the Process and Tools Design : Friction Stir Processing of Materials", vol. 47, no. September 2003, p. 4639, 2006.

[27] Rai, R., De, A., Bhadeshia, H. K. D. H., DebRoy, T., "Review: friction stir welding tools," Sci. Technol. Weld. Join. 16 (4), pp. 325 - 342, 2011.

[28] Palanivel, R., Koshy Mathews, P., Murugan, N., Dinaharan, I. "Effect of tool rotational speed and pin profile on microstructure and tensile strength of dissimilar friction stir welded AA5083-H111 and AA6351-T6 aluminum alloys", Mater. Des. 40, pp. 7 - 16, 2012.

[29] Boz, M., Kurt, A. "The influence of stirrer geometry on bonding and mechanical properties in friction stir welding process", Mater. Des. 25 (4), pp. 343 - 347, 2004.

[30] Mishra, R. S., Ma, Z. Y. "Friction stir welding and processing”, Mater. Sci. Eng. R Reports 50 (1-2), pp. 1 - 78, 2005.

[31] Shashi Kumar, S., Murugan, N., Ramachandran K. K. "Influence of tool material on mechanical and microstructural properties of friction stir welded $316 \mathrm{~L}$ austenitic stainless steel butt joints”, Int. J. Refract. Met. Hard Mater. 58, pp. 196 - 205, 2016.

[32] Darras, B. M., Khraisheh, M. K., Abu-Farha, F. K., Omar M. A. "Friction stir processing of commercial AZ31 magnesium alloy," J. Mater. Process. Technol. 191 (13), pp. $77-81,2007$.

[33] Keerthana, B., Vijaya Kumar, G., Anand Babu, K. "Effect of minimum quantity lubrication on surface roughness and temperature in milling of EN31 steel for die making", Strojnícky časopis - Journal of Mechanical Engineering 69 (1), pp. 61 - 68, 2019. DOI: $10.2478 /$ scjme-2019-0005

[34] de Giorgi, M.,Scialpi, A., Panella, F. W., de Filippis, L. A. C. "Effect of shoulder geometry on residual stress and fatigue properties of AA6082 FSW joints", J. Mech. Sci. Technol. 23 (1), pp. 26 - 35, 2009.

[35] Handa, A, Chawla, V. "Experimental evaluation of mechanical properties of friction welded dissimilar steels under varying axial pressures", Strojnícky časopis - Journal of Mechanical Engineering 66 (1), pp. 27 - 36, 2016. DOI: 10.1515/scjme-2016-0008

[36] Ramachandran, K. K., Murugan, N., S. K. S, “An Assessment on Friction Stir Welding of High Melting Temperature Materials", Applied Mechanics and Materials 594, pp. 43 $-47,2014$.

[37] Pilchak, A. L., Williams, J. C., "Microstructure and texture evolution during friction stir processing of fully lamellar Ti-6Al-4V", Metall. Mater. Trans. A Phys. Metall. Mater. Sci., vol. 42 (3), pp. 773 - 794, 2011.

[38] Feng, A. H., Ma, Z. Y. "Formation of Cu2FeA17phase in friction-stir-welded SiCp/AlCu-Mg composite,” Scr. Mater. 57 (12), pp. 1113 - 1116, 2007.

[39] R. S. Mishra, P. S. De, and N. Kumar, Friction Stir Welding and Processing. 2014.

[40] Siddiquee, A. N., Pandey, S. "Experimental investigation on deformation and wear of WC tool during friction stir welding ( FSW ) of stainless steel", 2014.

[41] Thompson, B., Babu, S. S. "Tool Degradation Characterization in the Friction Stir 
Welding of Hard Metals", Weld. J. 89 (12), pp. 256 - 261, 2010.

[42] Nathan, S. R., Malarvizhi, S., Balasubramanian, V., Rao, A. G. "Failure analysis of tungsten based tool materials used in friction stir welding of high strength low alloy steels", EFA 66, pp. 88 - 98, 2016.

[43] Gan, W., Li, Z. T., Khurana, S. "Tool materials selection for friction stir welding of L80 steel”, Sci. Technol. Weld. Join. 12 (7), pp. 610 - 613, 2007.

[44] García-Bernal, M. A., Mishra, R. S., Verma, R., Hernández-silva, D. "Influence of friction stir processing tool design on microstructure and superplastic behavior of AlMg alloys", Mater. Sci. Eng. A 670, pp. 9 - 16, 2016.

[45] Thomas, W. M., Nicholas, E. D., Smith, S. D. "Friction stir welding - tool developments," no. February, pp. $11-15,2001$.

[46] Buffa, G., Hua, J., Shivpuri, R., Fratini, L. "Design of the friction stir welding tool using the continuum based FEM model", Mater. Sci. Eng. A 419 (1-2), pp. 381 - 388, 2006.

[47] Fujii, H., Cui, L., Maeda, M., Nogi, K. "Effect of tool shape on mechanical properties and microstructure of friction stir welded aluminum alloys", 419, pp. 25 - 31, 2006.

[48] Colegrove, P. A., Shercliff, H. R. "Development of Trivex friction stir welding tool Part 1 - two-dimensional flow modelling and experimental validation”, 9 (4), pp. 345 - 351, 2004.

[49] Colegrove, P. A., Shercliff, H. R. "3-Dimensional CFD modelling of flow round a threaded friction stir welding tool profile,"169, pp. 320 - 327, 2005.

[50] Colegrove, P. A., Shercliff, H. R. "Development of Trivex friction stir welding tool Part 2 - three-dimensional flow modelling”, Sci. Technol. Weld. Join. 9 (4), pp. $352-361$, 2004.

[51] Elangovan, K., Balasubramanian, V. "Influences of tool pin profile and welding speed on the formation of friction stir processing zone in AA2219 aluminium alloy", J. Mater. Process. Technol. 200 (1-3), pp. 163 - 175, 2008.

[52] Elangovan, K., Balasubramanian, V. "Influences of pin profile and rotational speed of the tool on the formation of friction stir processing zone in AA2219 aluminium alloy," 459, pp. 7 - 18, 2007.

[53] H. K. Mohanty, M. M. Mahapatra, P. Kumar, P. Biswas, and N. R. Mandal, "Effect of Tool Shoulder and Pin Probe Profiles on Friction Stirred Aluminum Welds - a Comparative Study”, pp. 200 - 207, 2012.

[54] M. Skinner and R. L. Edwards, "Improvements to the FSW Process Using the SelfReacting Technology,” Mater. Sci. Forum 426-432, pp. 2849 - 2854, 2009.

[55] W. Y. Li et al., "Effects of tool rotational and welding speed on microstructure and mechanical properties of bobbin-tool friction-stir welded Mg AZ31," 64, pp. 714 - 720, 2014.

[56] P. L. Threadgill, M. M. Z. Ahmed, J. P. Martin, J. G. Perrett, and B. P. Wynne, "The use of bobbin tools for friction stir welding of aluminium alloys", Mater. Sci. Forum 642, pp. 1179 - 1184, 2010.

[57] Y. Huang, T. Wang, W. Guo, L. Wan, S. Lv, "Microstructure and surface mechanical property of AZ31 Mg / SiC p surface composite fabricated by Direct Friction Stir 
Processing," J. Mater. 59, pp. 274 -278, 2014.

[58] I. Galvão, R. M. Leal, D. M. Rodrigues, A. Loureiro, "Journal of Materials Processing Technology Influence of tool shoulder geometry on properties of friction stir welds in thin copper sheets", 213, pp. 129-135, 2013.

[59] Ø. Frigaard, Ø. Grong, and O. T. Midling "A Process Model for Friction Stir Welding of Age Hardening Aluminum Alloys”, 32, no. May, pp. 1189 - 1190, 2001.

[60] S. Lomolino, R. Tovo, and J. Santos "On the fatigue behaviour and design curves of friction stir butt-welded $\mathrm{Al}$ alloys", 27, pp. 305 - 316, 2005.

[61] M. N. James, D. G. Hattingh, and G. R. Bradley "Weld tool travel speed effects on fatigue life of friction stir welds in 5083 aluminium”, 25, pp. $1389-1398,2003$.

[62] M. Bahrami, M. K. Besharati Givi, K. Dehghani, and N. Parvin, "On the role of pin geometry in microstructure and mechanical properties of AA7075/SiC nano-composite fabricated by friction stir welding technique", Mater. Des. 53, pp. $519-527,2014$.

[63] G. Casalino, S. Campanelli, and M. Mortello, "Influence of Shoulder Geometry and Coating of the Tool on the Friction Stir Welding of Aluminium Alloy Plates", Procedia Eng. 69, pp. $1541-1548,2014$.

[64] P. K. Sahu and S. Pal, "Effect of Shoulder Diameter and Plunging Depth on Mechanical Properties and Thermal History of Friction Stir Welded Magnesium Alloy", 5th Int. 26th All India Manuf. Technol. Des. Res. Conf. (AIMTDR 2014), no. Aimtdr, pp. 12 $17,2014$.

[65] K. Ramanjaneyulu, G. Madhusudhan Reddy, and A. Venugopal Rao, "Role of Tool Shoulder Diameter in Friction Stir Welding: An Analysis of the Temperature and Plastic Deformation of AA 2014 Aluminium Alloy”, Trans. Indian Inst. Met. 67 (5), pp. $769-780,2014$.

[66] G. Padmanaban and V. Balasubramanian, "Selection of FSW tool pin profile, shoulder diameter and material for joining AZ31B magnesium alloy - An experimental approach”, Mater. Des. 30 (7), pp. 2647 - 2656, 2009.

[67] S. Malarvizhi and V. Balasubramanian, "Influences of tool shoulder diameter to plate thickness ratio $(\mathrm{D} / \mathrm{T})$ on stir zone formation and tensile properties of friction stir welded dissimilar joints of AA6061 aluminum-AZ31B magnesium alloys", Materials and Design 40, pp. 453 - 460, 2012.

[68] S. Hirasawa, H. Badarinarayan, K. Okamoto, and T. Tomimura, "Analysis of effect of tool geometry on plastic flow during friction stir spot welding using particle method", J. Mater. Process. Tech. 210 (11), pp. 1455 - 1463, 2010.

[69] H. Badarinarayan, Y. Shi, X. Li, and K. Okamoto, "International Journal of Machine Tools \& Manufacture Effect of tool geometry on hook formation and static strength of friction stir spot welded aluminum 5754-O sheets”, Int. J. Mach. Tools Manuf. 49 (11), pp. $814-823,2009$.

[70] I. Z. Radisavljevic, A. B. Zivkovic, V. K. Grabulov, N. A. Radovic, "Influence of pin geometry on mechanical and structural properties of butt friction stir welded 2024-T351 aluminum alloy", pp. 323 - 330, 2014.

[71] M. Azizieh, A. H. Kokabi, and P. Abachi, "Effect of rotational speed and probe profile on microstructure and hardness of AZ31 / $\mathrm{Al} 2 \mathrm{O} 3$ nanocomposites fabricated by friction stir processing”, Mater. Des. 32 (4), pp. 2034 - 2041, 2011. 
[72] G. Faraji and P. Asadi, "Characterization of AZ91 / alumina nanocomposite produced by FSP”, Mater. Sci. Eng. A 528 (6), pp. 2431 - 2440, 2011.

[73] M. Ilangovan, S. R. Boopathy, and V. Balasubramanian, "Effect of tool pin profile on microstructure and tensile properties of friction stir welded dissimilar AA 6061 e AA 5086 aluminium alloy joints”, Def. Technol. 11 (2), pp. 174 - 184, 2015.

[74] M. Rezaee, M. Farahani, S. Amir, and D. Alavi, "Investigation on the effects of tool geometry on the microstructure and the mechanical properties of dissimilar friction stir welded polyethylene and polypropylene sheets", J. Manuf. Process., vol. 26, pp. 269 279, 2017.

[75] K. Colligan, "Material Flow Behavior during Friction Stir Welding of Aluminum”, no. July, pp. 229 - 237, 1999.

[76] M. Guerra, C. Schmidt, J. C. Mcclure, L. E. Murr, and A. C. Nunes, "Flow patterns during friction stir welding", 49, pp. 95 - 101, 2003.

[77] X. Cao and M. Jahazi, "Effect of welding speed on the quality of friction stir welded butt joints of a magnesium alloy", Mater. Des. 30 (6), pp. 2033 - 2042, 2009.

[78] S. M. Chowdhury, D. L. Chen, S. D. Bhole, and X. Cao, "Effect of pin tool thread orientation on fatigue strength of friction stir welded AZ31B-H24 Mg butt joints", Procedia Eng. 2 (1), pp. 825 -833, 2010.

[79] T. U. Seidel and A. P. Reynolds, "Visualization of the Material Flow in AA2195 Friction-Stir Welds Using a Marker Insert Technique", 32, no. November, pp. $7-8$, 2001.

[80] M. Fairman, N. Afrin, D. L. Chen, X. Cao, and M. Jahazi, "Microstructural evaluation of friction stir processed \{AZ31B-H24\} magnesium alloy," Can. Metall. Q. 46, no. April, pp. 425 - 432, 2007.

[81] A. Kumar and P. Biswas, "Effect of tool pin profile on the material flow characteristics of AA6061", J. Manuf. Process. 26, pp. 382 - 392, 2017.

[82] K. P. Mehta and V. J. Badheka, "Effects of Tilt Angle on Properties of Dissimilar Friction Stir Welding Copper to Aluminum," Mater. Manuf. Process. 31, no. January 2015, pp. $37-41,2014$.

[83] R. A. Prado, L. E. Murr, K. F. Soto, and J. C. McClure, "Self-optimization in tool wear for friction-stir welding of Al 6061+20\% Al2O3MMC", Mater. Sci. Eng. A 349 (1-2), pp. $156-165,2003$.

[84] K. R. Seighalani, M. K. B. Givi, A. M. Nasiri, and P. Bahemmat, "Investigations on the Effects of the Tool Material, Geometry, and Tilt Angle on Friction Stir Welding of Pure Titanium”, 19, no. October, pp. 955 - 962, 2010.

[85] Z. W. Chen and S. Cui, "On the forming mechanism of banded structures in aluminium alloy friction stir welds", 58, pp. $417-420,2008$.

[86] W. International, L. M. Welding, R. Jl, and I. Technology, "Mechanical properties of friction stir welded 6061 aluminium", 18 (2), pp. 95 - 102, 2004.

[87] Barlas, Z., Ozsarac, U. "Effects of FSW Parameters on Joint Properties of AlMg3 Alloy," Weld. J. 91 (1), pp. 16 - 22, 2012.

[88] M. H. Tolephih, H. M. Mahmood, and H. H. Esam, "Effect of tool offset and tilt angle on weld strength of butt joint friction stir welded specimens of AA2024 aluminum alloy 
welded to commercial pure cupper", 3 (4), 2013.

[89] M. Elyasi, H. A. Derazkola, M. Hosseinzadeh, "Investigations of tool tilt angle on properties friction stir welding of A441 AISI to AA1100 aluminium," Proc. Inst. Mech. Eng. Part B J. Eng. Manuf. 230 (7), pp. 1234-1241, 2016.

[90] J. Wang, J. Su, R. S. Mishra, R. Xu, and J. A. Baumann, "Tool wear mechanisms in friction stir welding of Ti-6Al-4V alloy," Wear 321, pp. 25 - 32, 2014.

[91] M. Zhao, Z. Zhou, Q. Ding, M. Zhong, and K. Arshad, "Effect of rare earth elements on the consolidation behavior and microstructure of tungsten alloys", Int. J. Refract. Met. Hard Mater. 48, pp. 19 - 23, 2015.

[92] Klingensmith, A. A. R. M. S., Dupont, J. N. "Microstructural Characterization of a Double-Sided Friction Stir Weld on a Superaustenitic Stainless Steel”, Weld. Res., pp. $77-86,2005$.

[93] A. P. Reynolds, W. Tang, M. Posada, and J. Deloach, "Friction stir welding of DH36 steel", 8 (6), 2003.

[94] C. D. Sorensen and A. L. Stahl, "Experimental Measurements of Load Distributions on Friction Stir Weld Pin Tools”, 38, no. June, pp. 451 - 459, 2007.

[95] A. Arora, M. Mehta, A. De, and T. Debroy, "Load bearing capacity of tool pin during friction stir welding”, Int. J. Adv. Manuf. Technol. 61 (9-12), pp. 911 - 920, 2012.

[96] H. J. Liu, J. C. Feng, H. Fujii, and K. Nogi, "Wear characteristics of a WC-Co tool in friction stir welding of AC4A+30 vol\%SiCp composite", Int. J. Mach. Tools Manuf., 45 (14), pp. 1635 - 1639, 2005.

[97] Manvatkar, V. D., Arora, A., Debroy, T. "Neural network models of peak temperature , torque , traverse force, bending stress and maximum shear stress during friction stir welding”, 17 (6), pp. 460 - 466, 2012.

[98] Khandkar, M. Z. H., Khan, J. A., Reynolds, A. P. "Prediction of temperature distribution and thermal history during friction stir welding : input torque based model", Science and Technology of Welding \& Joining 8(3), pp. 165-174, 2003.

[99] Trimble, D., Monaghan, J., O’Donnell, G. E., Donnell, G. E. O. "Force generation during friction stir welding of AA2024-T3," CIRP Ann. - Manuf. Technol. 61 (1), pp. 9 $-12,2012$.

[100] DebRoy, T., De, A., Bhadeshia, H. K. D. H., Manvatkar, V. D., Arora, A. "Tool durability maps for friction stir welding of an aluminium alloy", Proc. R. Soc. A Math. Phys. Eng. Sci. 468 (2147), pp. 3552 - 3570, 2012.

[101] de Saracibar, C. A. M. Chiumenti, Cervera, M., Dialami, N., and Seret, A. "Computational Modeling and Sub-Grid Scale Stabilization of Incompressibility and Convection in the Numerical Simulation of Friction Stir Welding Processes", Arch. Comput. Methods Eng. 21 (1), pp. 3 - 37, 2014.

[102] Su, H., Song, C., Bachmann, M., M. Rethmeier, M. "Numerical modeling for the effect of pin profiles on thermal and material flow characteristics in friction stir welding", J. Mater. 77, pp. 114 - 125, 2015.

[103] Buchibabu, V., Reddy, G. M., De, A. "Probing torque, traverse force and tool durability in friction stir welding of aluminum alloys", J. Mater. Process. Technol., 241, pp. $86-$ 92, 2017. 
[104] Kumar, S. "ScienceDirect Ultrasonic assisted friction stir processing of 6063 aluminum alloy", Arch. Civ. Mech. Eng. 16 (3), pp. 473 - 484, 2016. 